\title{
Functional Nicotinic Acetylcholine Receptors Containing $\alpha 6$ Subunits Are on GABAergic Neuronal Boutons Adherent to Ventral Tegmental Area Dopamine Neurons
}

\author{
Kechun Yang, ${ }^{1,4}$ Lori Buhlman, ${ }^{2}$ Ghous M. Khan, ${ }^{3}$ Robert A. Nichols, ${ }^{3}$ Guozhang Jin, ${ }^{4}$ J. Michael McIntosh, ${ }^{5}$ \\ Paul Whiteaker, ${ }^{2}$ Ronald J. Lukas, ${ }^{2}$ and Jie $\mathrm{Wu}^{1}$ \\ Divisions of ${ }^{1}$ Neurology and ${ }^{2}$ Neurobiology, Barrow Neurological Institute, St. Joseph's Hospital and Medical Center, Phoenix, Arizona 85013-4496, \\ ${ }^{3}$ Department of Physiology and Pharmacology, John A. Burns School of Medicine, University of Hawaii at Manoa, Honolulu, Hawaii 96813, ${ }^{4}$ Department of \\ Pharmacology, Shanghai Institute of Materia Medica, Chinese Academy of Sciences, Shanghai 201203, China, and ${ }^{5}$ Departments of Biology and Psychiatry, \\ University of Utah, Salt Lake City, Utah 84112
}

Diverse nicotinic acetylcholine receptor (nAChR) subtypes containing different subunit combinations can be placed on nerve terminals or soma/dendrites in the ventral tegmental area (VTA). nAChR $\alpha 6$ subunit message is abundant in the VTA, but $\alpha 6^{*}$-nAChR cellular localization, function, pharmacology, and roles in cholinergic modulation of dopaminergic (DA) neurons within the VTA are not well understood. Here, we report evidence for $\alpha 6 \beta 2^{\star}$-nAChR expression on GABA neuronal boutons terminating on VTA DA neurons. $\alpha$-Conotoxin ( $\alpha$-Ctx) MII labeling coupled with immunocytochemical staining localizes putative $\alpha 6^{*}$-nAChRs to presynaptic GABAergic boutons on acutely dissociated, rat VTA DA neurons. Functionally, acetylcholine (ACh) induces increases in the frequency of bicuculline-, picrotoxin-, and 4-aminopyridine-sensitive miniature IPSCs (mIPSCs) mediated by $\mathrm{GABA}_{\mathrm{A}}$ receptors. These increases are abolished by $\alpha 6^{*}$-nAChR-selective $\alpha$-Ctx MII or $\alpha$-Ctx PIA (1 nм) but not by $\alpha 7$ (10 nм methyllycaconitine) or $\alpha 4^{*}(1 \mu \mathrm{m}$ dihydro- $\beta$-erythroidine)$\mathrm{nAChR}$-selective antagonists. ACh also fails to increase mIPSC frequency in VTA DA neurons prepared from nAChR $\beta 2$ knock-out mice. Moreover, ACh induces an $\alpha$-Ctx PIA-sensitive elevation in intraterminal $\mathrm{Ca}^{2+}$ in synaptosomes prepared from the rat VTA. Subchronic exposure to $500 \mathrm{~nm}$ nicotine reduces ACh-induced GABA release onto the VTA DA neurons, as does $10 \mathrm{~d}$ of systemic nicotine exposure. Collectively, these results indicate that $\alpha 6 \beta 2^{*}$-nAChRs are located on presynaptic GABAergic boutons within the VTA and modulate GABA release onto DA neurons. These presynaptic $\alpha 6 \beta 2^{\star}-$ nAChRs likely play important roles in nicotinic modulation of DA neuronal activity.

\section{Introduction}

Dopaminergic (DA) neurons in the ventral tegmental area (VTA) express several nicotinic acetylcholine receptor (nAChR) subunits, including $\alpha 3-\alpha 7$ and $\beta 2-\beta 4$ (Klink et al., 2001; Wooltorton et al., 2003; Azam et al., 2007; Yang et al., 2009a). These subunits can combine to form homomeric $\alpha 7-\mathrm{nAChRs}$ (Wonnacott, 1997) or heteromeric non- $\alpha 7-\mathrm{nAChRs}$ (Klink et al., 2001; Yang et al., 2009a), including $\alpha 4^{*}-\mathrm{nAChRs}$ and $\alpha 6^{*}-\mathrm{nAChRs}$ (where the ${ }^{\star}$ indicates that $\mathrm{nAChR}$ subunits in addition to those specified also are or may be part of the complex). To date, among

Received June 11, 2010; revised Nov. 30, 2010; accepted Dec. 13, 2010.

This work was supported by Arizona Biomedical Research Commission Grants 0028 and 0057, the Institute for Mental Health Research, and the Philip Morris International External Research Program (R.J.L., 2005-2010; J.W., 2007-2010), the Barrow Neurological Foundation (Robert and Gloria Wallace Foundation and Marjorie Newsome and Sandra Solheim Aiken funds), and National Institutes of Health Grants NS040417 (R.J.L., J.W.), DA015389 (R.J.L., J.W.), DA012242 (P.W., J.M.M.), MH053631 and GM048677 (J.M.M.), and AG021586 (R.A.N.). We thank Dr. Marina Picciotto of Yale University for providing $\beta 2 \mathrm{KO}$ mice.

Correspondence should be addressed to Dr. Jie Wu, Division of Neurology, Barrow Neurological Institute, St. Joseph's Hospital and Medical Center, 350 West Thomas Road, Phoenix, AZ 85013-4496. E-mail: Jie.Wu@chw.edu.

R. A. Nichols' present address: Department of Cell and Molecular Biology, Drexel University College of Medicine, Philadelphia, PA 19102.

DOI:10.1523/JNEUROSCI.3003-10.2011

Copyright $\odot 2011$ the authors $\quad 0270-6474 / 11 / 312537-12 \$ 15.00 / 0$ the nAChRs on VTA neurons, $\alpha 7-\mathrm{nAChRs}$ and $\alpha 4 \beta 2-\mathrm{nAChRs}$ have both been extensively studied (Wooltorton et al., 2003; Yang et al., 2009a). $\alpha 4 \beta 2-n A C h R s$ represent the majority of functional heteromeric nAChRs on DA neuron somata (Champtiaux et al., 2003; Pons et al., 2008). $\alpha 4 \beta 2-n A C h R s$ have been implicated in nicotine self-administration and in reinforcement of other biologically rewarding events, suggesting roles not only in nicotine addiction but perhaps also in other drug abuse processes (Clarke, 1991; Dani and Heinemann, 1996). $\alpha 7$-nAChRs have been implicated in the control of excitatory glutamate actions in the VTA (Wooltorton et al., 2003; Yang et al., 2009a). However, the impact of $\alpha 6^{*}-\mathrm{nAChR}$ function on DA cell activity within the VTA is not well understood.

The nAChR $\alpha 6$ subunit is not widely expressed in the brain, but it is abundant in midbrain DA regions associated with pleasure, reward, and mood control (Klink et al., 2001; Azam et al., 2002; Champtiaux et al., 2003; Pons et al., 2008), suggesting that $\alpha 6^{*}$-nAChRs may play critical roles in nicotinic reward and in the modulation of mood by nicotine (Shytle et al., 2002). However, it has been controversial as to whether these effects are mediated by $\alpha 6^{*}-\mathrm{nAChRs}$ expressed on DA neuronal soma and/or dendrites or on presynaptic terminals/boutons associated 
with VTA DA neurons. $\alpha 6$ and other nAChR subunits are reported to form functional $\alpha 6^{*}-\mathrm{nAChRs}$ located on DA neuronal soma in "hypersensitive" mutant $\alpha 6$ subunit transgenic mice (Drenan et al., 2008). However, using acutely dissociated VTA DA neurons, we demonstrated that nicotinic whole-cell currents mediated by nAChRs expressed on DA neuronal soma are insensitive to the $\alpha 6^{*}-\mathrm{nAChR}$-selective antagonist $\alpha$-conotoxin $(\alpha$ Ctx) MII (Yang et al., 2009a). In contrast, several studies indicate that $\alpha 6^{*}-\mathrm{nAChRs}$ are located on VTA DA neuronal terminals, in which they modulate neurotransmitter release in multiple brain regions (Champtiaux et al., 2003; Salminen et al., 2004; Gotti et al., 2005; Meyer et al., 2008). Moreover, there is evidence for $\alpha 3 \beta 2^{\star}-\mathrm{nAChR}$ and/or $\alpha 6 \beta 2^{*}-\mathrm{nAChR}$ expression on GABAergic neuronal terminals in the superior colliculus (Endo et al., 2005). Furthermore, we found that $100 \mathrm{~nm} \alpha$-Ctx MII completely prevented acetylcholine (ACh)-induced increases in the frequency of miniature IPSC (mIPSC) evoked in bouton-decorated VTA DA neurons, suggesting the expression of functional, $\alpha$-Ctx MIIsensitive $\alpha 6^{*}-\mathrm{nAChRs}$ or $\alpha 3^{*}-\mathrm{nAChRs}$ that can modulate neurotransmitter release (Yang et al., 2009a).

The objective of this study was to extend our previous work and test the hypothesis that $\alpha 6^{*}-\mathrm{nAChRs}$ in the VTA are expressed on presynaptic terminals/boutons, in which they could play crucial roles in modulating GABA release onto DA neurons.

\section{Materials and Methods}

Preparation of bouton-adherent single neurons from the VTA

For the present study, we chose postnatal day 14 (P14) to P30 animals (both male and female) based on the observation that, during postnatal days $\mathrm{P} 14-\mathrm{P} 40$, there is no significant alteration in $\mathrm{nAChR} \alpha 6$ subunit mRNA levels in the rat VTA (Azam et al., 2007). Single neurons were mechanically dissociated from the VTAs of Wistar rats or of wild-type (WT) or nAChR $\beta 2$ subunit knock-out (KO) mice, as described previously (Akaike and Moorhouse, 2003; Xiao et al., 2009b). Briefly, animals were anesthetized using a mixture of ketamine, xylazine, and acepromazine and killed by cervical dislocation. Ice-cold, glycerol-containing artificial CSF (ACSF) (in mM: 250 glycerol, $2.5 \mathrm{KCl}, 1.2 \mathrm{NaH}_{2} \mathrm{PO}_{4}, 1.2$ $\mathrm{MgCl}_{2}, 2.4 \mathrm{CaCl}_{2}, 26 \mathrm{NaHCO}_{3}$, and 11 glucose, titrated to $\mathrm{pH} 7.4$ ) was perfused transcardially $(20-40 \mathrm{ml}$ ) before decapitation (Ye et al., 2006). A brain block containing the midbrain region was isolated, glued onto a cutting stage, and embedded with $2 \%$ high-strength low-gel point agarose (agarose type I-B). The stage with the glued tissue was then transferred into the hole of the chamber of a VF-100 slicing microtome (Precision Instruments), which was filled with $4^{\circ} \mathrm{C}$ glycerol-ACSF saturated with $95 \% \mathrm{O}_{2}-5 \% \mathrm{CO}_{2}$. Coronal sections of $400 \mu \mathrm{m}$ thickness were cut, and each slice was transferred immediately to a recovery bath $\left(31^{\circ} \mathrm{C}\right)$ for $30 \mathrm{~min}$ and then kept at room temperature $\left(22-24^{\circ} \mathrm{C}\right)$ for at least $1 \mathrm{~h}$ before dissociation. The recovery bath solution was standard oxygenated (95\% $\mathrm{O}_{2}-5 \% \mathrm{CO}_{2}$ ) ACSF containing (in $\mathrm{mm}$ ) the following: $125 \mathrm{NaCl}$, $2.5 \mathrm{KCl}, 1.2 \mathrm{NaH}_{2} \mathrm{PO}_{4}, 1.2 \mathrm{MgCl}_{2}, 2.4 \mathrm{CaCl}_{2}, 26 \mathrm{NaHCO}_{3}$, and 11 glucose, titrated to $\mathrm{pH}$ 7.4. After incubation, one of the slices containing the VTA region was transferred into a $35 \mathrm{~mm}$ dish, and the VTA region was identified visually using an inverted microscope (IX70; Olympus) as medial to the accessory optic tract and lateral to fasciculus retroflexus with reference to the substantia nigra (supplemental Fig. $1 \mathrm{~B}$, available at www. jneurosci.org as supplemental material) according to a brain atlas (Paxinos and Watson, 1998). A heavily fire-polished glass pipette $(\sim 5 \mu \mathrm{m}$ tip diameter), lightly touching the surface of the VTA, was vibrated horizontally at $30-40 \mathrm{~Hz}$ for $2 \mathrm{~min}$. The slice was then removed, and the isolated neurons were allowed to adhere to the bottom of the dish within $20 \mathrm{~min}$ (supplemental Fig. $1 \mathrm{~A}$, available at www.jneurosci.org as supplemental material). The described protocol for the preparation of mechanically dissociated single neurons from rodent VTA was approved by the Institutional Animal Care and Use Committee of the Barrow Neurological Institute.

\section{Perforated patch-clamp whole-cell recordings}

We mainly used perforated patch, whole-cell current recording for characterization of functional nAChRs in single dissociated neurons, as described previously (Yang et al., 2009a). Briefly, a culture dish containing dissociated cells placed on the stage of an inverted microscope (Olympus IX7) for visual monitoring was continuously superfused with standard external solution containing the following (in $\mathrm{mm}$ ): $150 \mathrm{NaCl}, 5 \mathrm{KCl}, 1$ $\mathrm{MgCl}_{2}, 2 \mathrm{CaCl}_{2}, 10$ glucose, and 10 HEPES, $\mathrm{pH}$ 7.4. Atropine sulfate $(0.5$ $\mu \mathrm{M})$ was added into external solution to block muscarinic receptors. This atropine concentration has little effect on nicotine-induced currents (Wu et al., 2004). Recording electrodes fashioned on a two-stage pipette puller (3-5 M $\Omega$; P-830; Narishige) were filled with the appropriate intracellular solution containing $150 \mathrm{~mm} \mathrm{KCl}$ and $10 \mathrm{~mm}$ HEPES, pH 7.2 (with TrisOH), supplemented with amphotericin B $(200-240 \mu \mathrm{g} / \mathrm{ml})$ from a $40 \mathrm{mg} / \mathrm{ml}$ stock prepared in DMSO. The pipette solution containing amphotericin B was usually used within $4 \mathrm{~h}$. After the patch pipette formed a seal $(>2 G \Omega)$, a perforated whole-cell conformation was formed as judged by gradual (5-15 min) reduction of the access resistance (to $<60 \mathrm{M} \Omega$ ). The seal was usually stable for at least 30-60 min without current response rundown. The currents were recorded using a patch-clamp amplifier (200B; Molecular Devices), and data were collected at $10 \mathrm{kHz}$, filtered at $2 \mathrm{kHz}$, displayed and digitized online (Clampex9.0, Molecular Devices Digidata 1322 series analog-to-digital board), and stored to a computer hard drive. Focally applied drugs were rapidly delivered into the bath medium by a computer-controlled "U-tube" application system (Yang et al., 2009a).

During perforated patch-clamp, whole-dell current recording, we often found events that under our recording conditions that appeared as mIPSCs. These events occurred spontaneously (i.e., we did not use electrical stimulation of acutely dissociated cells). The events occurred in the presence of $50 \mu \mathrm{M}$ DL-2-amino-5-phosphono-valeric acid (APV) and 20 $\mu_{\mathrm{M}}$ 3-dihydroxy-6-nitro-7-sulfamoyl-benzo[f] quinoxaline-2,3-dione (NBQX), and they were not affected by the additional presence of $0.3 \mu \mathrm{M}$ tetrodotoxin (TTX), meaning that their appearance did not depend on action potential propagation.

\section{Electrophysiological data analysis and statistics}

Data were analyzed offline. We screened for mIPSCs automatically using a template and mini-analysis (Synaptosoft), but all events for additional analysis were confirmed manually/visually. Experiments were performed using single neurons recorded at room temperature. Recordings from single dissociated VTA neurons had lower background noise at room temperature than slice recordings done at physiological temperature (Trigo et al., 2010). Thus, the noise levels of our single neuron recordings were lower. In general, we set $3-5 \mathrm{pA}$ as the threshold level for mIPSCs recorded in single neurons and set a higher threshold level (10-20 pA) for mIPSC recorded in slices. We then also manually checked and accepted or rejected events using rise and decay times as criteria. More than $95 \%$ of the mIPSCs that were selected by automated screening met visu$\mathrm{al} /$ manual criteria for additional analysis. The frequency and amplitude of mIPSCs in different conditions were measured. Data were given as mean values \pm SEM for $n$ number of independent assessments. A probability level of $p<0.05$ was considered to be statistically significant. We used ANOVA for multiple group comparisons, paired $t$ test for the same neuron before and after treatment, and unpaired $t$ test for comparisons when analysis of two groups was involved.

\section{Immunocytochemistry, presynaptic labeling, and ligand binding studies}

Tyrosine hydroxylase immunostaining. Dissociated VTA neurons were fixed with $4 \%$ paraformaldehyde for $15 \mathrm{~min}$, rinsed three times with PBS, and treated with saponin $(1 \mathrm{mg} / \mathrm{ml}$; Sigma-Aldrich) for $5 \mathrm{~min}$ as a permeabilizing agent. After rinsing four times with PBS, the neurons were incubated at room temperature in anti-tyrosine hydroxylase primary antibody (AB152; Millipore Bioscience Research Reagents) diluted 1:1000 in HBSS (supplemented with $5 \%$ bovine serum albumin as a blocking agent) for $30 \mathrm{~min}$. After another three rinses with PBS, a secondary antibody (cyanine 3-conjugated, anti-mouse IgG; SigmaAldrich) was applied at room temperature for $30 \mathrm{~min}$ (diluted 1:100). 
After rinsing a final three times with PBS, the labeled cells were visualized using fluorescence microscopy.

FM 1-43 staining. FM 1-43 [N-(3-triethylammoniumpropyl)-4-(4(dibutylamino)styryl) pyridinium dibromide] (Invitrogen) at a concentration of $10 \mathrm{~mm}$ in $45 \mathrm{~mm}$ high $\mathrm{K}^{+}$solution, in which $40 \mathrm{~mm} \mathrm{NaCl}$ in a standard external solution was replaced with equimolar $\mathrm{KCl}$, was perfused across a dissociated single neuron for $30 \mathrm{~s}$ and then was washed out with the standard external solution. The fluorescent spots, indicating the existence of putative presynaptic boutons, were visualized using fluorescence microscopy (IX70-S1F2; Olympus) (Akaike and Moorhouse, 2003).

Ligand binding studies and GAD65/67 immunostaining. Dissociated neurons were fixed for $10 \mathrm{~min}$ in $4 \%$ freshly prepared paraformaldehyde at $4^{\circ} \mathrm{C}$. After two 5-min rinses with PBS, cells were permeabilized for 1 min with $0.1 \mathrm{M}$ Tris-HCl, pH 7.2, containing $0.25 \%$ Triton X-100 and Nonidet P-40, after which endogenous peroxidases were quenched by incubating cells in $0.3 \% \mathrm{H}_{2} \mathrm{O}_{2}$ for $15 \mathrm{~min}$, and the cells were rinsed for an additional $5 \mathrm{~min}$ in PBS. Nonspecific binding was blocked with tyramide signal amplification (TSA) kit (PerkinElmer Life and Analytical Sciences) blocking reagent for $30 \mathrm{~min}$. Cells were then incubated for $10 \mathrm{~min}$ in ice-cold conotoxin binding buffer (as described by Whiteaker et al., 2000): $144 \mathrm{~mm} \mathrm{NaCl}, 1.5 \mathrm{~mm} \mathrm{KCl}, 2 \mathrm{mM} \mathrm{CaCl}_{2}, 1 \mathrm{~mm} \mathrm{MgSO}_{4}, 20 \mathrm{~mm}$ HEPES, pH 7.5, plus $0.1 \%$ BSA and 1 mm phenylmethylsulfonylfluoride. Tested cells were incubated in conotoxin binding buffer containing 0.5 nм biotinylated $\alpha$-Ctx MII, $10 \mu \mathrm{g} / \mathrm{ml}$ each of aprotinin, leupeptin, and pepstatin A, and 5 mм EDTA and 5 mм EGTA for $2 \mathrm{~h}$ at room temperature. To demonstrate signal specificity, control samples were incubated in conotoxin binding buffer containing $0.5 \mathrm{~nm}$ biotinylated $\alpha$-Ctx MII and $10 \mu \mathrm{M}$ epibatidine. Unbound conotoxin was washed away with two brief rinses in each of the following: ice-cold conotoxin buffer, ice-cold $0.1 \times$ conotoxin buffer, and 5 mM HEPES, $\mathrm{pH} 7.5$. After washing, the TSA process was used to identify and amplify the bound $\alpha$-Ctx MII signal. More specifically, streptavidin-conjugated horse radish peroxidase (HRP) was diluted 1:100 in TSA blocking reagent and was added to the cells for $30 \mathrm{~min}$ to allow streptavidin-HRP to bind biotin, followed by three 5-min rinses in TNT wash buffer $(0.1 \mathrm{M}$ Tris- $\mathrm{HCl}, 0.15 \mathrm{M} \mathrm{NaCl}$, and $0.05 \%$ Tween 20, pH 7.5). Cy5-conjugated tyramide (an HRP substrate) was diluted 1:50 in amplification diluent (TSA kit component) and was added to the cells for 30 min to allow Cy5-tyramide to covalently bind tyrosines in the proximity of immobilized HRP. To saturate unbound biotin on $\alpha$-Ctx MII, endogenous biotin, and biotin-binding proteins, cells were incubated in a streptavidin solution, followed by a biotin solution for $15 \mathrm{~min}$ each (Vector Laboratories). The locally, HRP-catalyzed deposition of fluorescent conjugates allows for large amplification of toxin binding signal, and use of the $\mathrm{Cy} 5$-conjugated tyramide reagent was preferred because it gave fluorescence in red wavelengths removed from autofluorescence in green wavelengths commonly seen in tissue sections.

Cells were then briefly washed in PBS, and test cells were incubated overnight at $4^{\circ} \mathrm{C}$ in rabbit anti-glutamic acid decarboxylase (GAD) (1: 1000 in PBS; AB1511; Millipore Bioscience Research Reagents); primary antibody was eliminated for control cells. After incubation in primary antibody, cells were rinsed twice in PBS for $5 \mathrm{~min}$ and then incubated 60 $\min$ in $3 \mu \mathrm{g} / \mathrm{ml}$ biotinylated goat, anti-rabbit secondary antibody (Jackson ImmunoResearch) diluted in PBS, and 2\% normal horse serum. Secondary antibody was washed out three times for $5 \mathrm{~min}$ in TNT wash buffer, after which the TSA process was used as described previously, using fluoresceinconjugated tyramide. Images were captured with a Carl Zeiss confocal microscope used in conjunction with Carl Zeiss LSM software.

Chronic nicotine treatment in vivo. Rats were randomly divided into two subgroups from the same litter, and these animals were exposed to 10 successive days of single injections of either nicotine tartrate adequate to produce brain levels of free base nicotine like those achieved in human smokers $\left(0.5 \mathrm{mg} \cdot \mathrm{kg}^{-1} \cdot \mathrm{d}^{-1}\right.$, i.p., to produce brain levels of $\left.\sim 600 \mathrm{nM}\right)$ (Rowell and Li, 1997) or vehicle, beginning on postnatal day 14. Twentyfour hours (or $5 \mathrm{~d}$ ) after the last nicotine injection, vehicle- or nicotinetreated animals were used to generate acutely dissociated neurons from the VTA.

Preparation and $\mathrm{Ca}^{2+}$ imaging of individual VTA synaptosomes. Intact, isolated presynaptic nerve terminals (synaptosomes) from VTA were purified using the Percoll step gradient method (Dunkley et al., 1986). In brief, brains from postnatal 28 - to 30 -d-old rats were removed into icecold $0.32 \mathrm{M}$ sucrose, and the midbrain region was sliced out using standard external landmarks. The VTA was identified using a rat brain atlas (Paxinos and Watson, 1998) and dissected under ice-cold $0.32 \mathrm{~m}$ sucrose. The tissue was rapidly homogenized in ice-cold $0.32 \mathrm{M}$ sucrose with a glass-Teflon tissue grinder, and the synaptosomes were isolated as described previously (Nayak et al., 2001). The purified synaptosomes were washed with oxygenated HEPES-buffered saline (HBS), $\mathrm{pH} 7.4$, containing the following (in $\mathrm{mm}$ ): $142 \mathrm{NaCl}, 2.4 \mathrm{KCl}, 1.2 \mathrm{~K}_{2} \mathrm{HPO}_{4}, 1 \mathrm{MgCl}_{2}$,

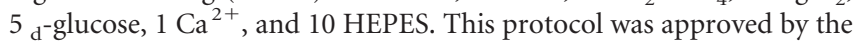
Drexel University College of Medicine Institutional Animal Care and Use Committee. For $\mathrm{Ca}^{2+}$ imaging, the purified synaptosome preparation was loaded with Fluo-4 (Invitrogen) using the AM derivative at $5 \mu \mathrm{M}$ in oxygenated HBS for $60 \mathrm{~min}$ at $37^{\circ} \mathrm{C}$. The Fluo-4-loaded preparation was then washed with HBS by centrifugation and plated onto glass coverslips coated with Cell Tak (BD Biosciences). The synaptosome-bound coverslips were mounted in a rapid-exchange Warner perfusion system attached to a Nikon PCM 2000 laser-scanning confocal microscope and perfused with oxygenated HBS containing $0.5 \mu \mathrm{M}$ atropine (see above, Perforated patch-clamp whole-cell recordings) was started. Perfusion was continued without (control) or with $1 \mathrm{nM} \alpha$-Ctx PIA for 10 min or 50 nM $\alpha$-bungarotoxin $(\alpha$-BgTx) for $30 \mathrm{~min}$. In response to $488 \mathrm{~nm}$ excitation, digitized fluorescent images were then captured at 2 or $4 \mathrm{~s}$ intervals, with the first five images collected as baseline, while the preparation was under continuous perfusion $(\sim 3 \mathrm{ml} / \mathrm{min})$. After recording the baseline (only the end of the baseline shown), the perfusate was switched to HBS containing $1 \mathrm{~mm}$ acetylcholine $(\mathrm{ACh})$ or $30 \mathrm{~mm} \mathrm{KCl}$. Fluorescent intensities associated with individual synaptosomes were quantified using MetaMorph (Molecular Devices) and corrected for photobleaching based on the baseline ( $<3 \%$ per interval), by an observer blind to the experimental conditions. Data are presented as normalized responses $\left(F / F_{0}\right.$, where $F_{0}$ is the intensity at $\left.t_{0}\right)$. Sample number $(n)$ refers to the number of individual synaptosomes in the results pooled across three replicate experiments, presented as mean values \pm SEM

Chemicals. The drugs used in the present study were (-)nicotine tartrate, ACh, choline, methyllycaconitine (MLA), $\alpha$-BgTx, dihydro- $\beta$ erythroidine (DH $\beta \mathrm{E}), \mathrm{DA}, 4$-aminopyridine (4-AP), TTX, APV, NBQX, and bicuculline (BMI) (all purchased from Sigma-Aldrich) and RJR2403 [ $(E)$-N-methyl-4-pyridin-3-ylbut-3-en-1-amine] (purchased from Tocris Cookson). Fluo-4/AM and FM 1-43 were purchased from Invitrogen. $\alpha$-Ctx MII and $\alpha$-Ctx PIA were synthesized as described previously (Dowell et al., 2003). Biotinylated $\alpha$-Ctx MII was prepared by 9-fluorenylmethoxycarbonyl (Fmoc) solid-phase synthesis. After assembly of the linear peptide, the N-terminal Fmoc group was removed, and biotin was coupled to the $\alpha$-amino group of the $\mathrm{N}$ terminus using $N, N^{\prime}$ didsopropylcarbodiimide with 1-hydroxybenzotriazole in $\mathrm{N}$-methyl-2pyrrolidone. The derivatized peptide was cleaved from the resin, disulfide bonds oxidized, and peptide purified by previously described methods (Cartier et al., 1996; Dowell et al., 2003).

\section{Results}

$\alpha$-Ctx MII-labeled presynaptic nAChRs on GABAergic boutons in an acutely dissociated, bouton-adherent, neuronal preparation from rat VTA

Initial experiments were designed to determine which $\mathrm{nAChR}$ subtype(s) reside on presynaptic boutons associated with rat VTA DA neurons and are candidates for nicotinic modulation of neurotransmitter release. To achieve this goal, we used mechanically dissociated neurons from the VTA that retained adherent, presynaptic nerve endings or boutons (Deng et al., 2009; Xiao et al., 2009a). This preparation offers the unique advantage of allowing measurement of synaptic currents on identified neurons while providing unimpeded access to distinct presynaptic receptor populations. Compared with use of brain slices or primary cultured neurons, the bouton-containing neuronal preparation has at least four inherent advantages: (1) rapid drug application 

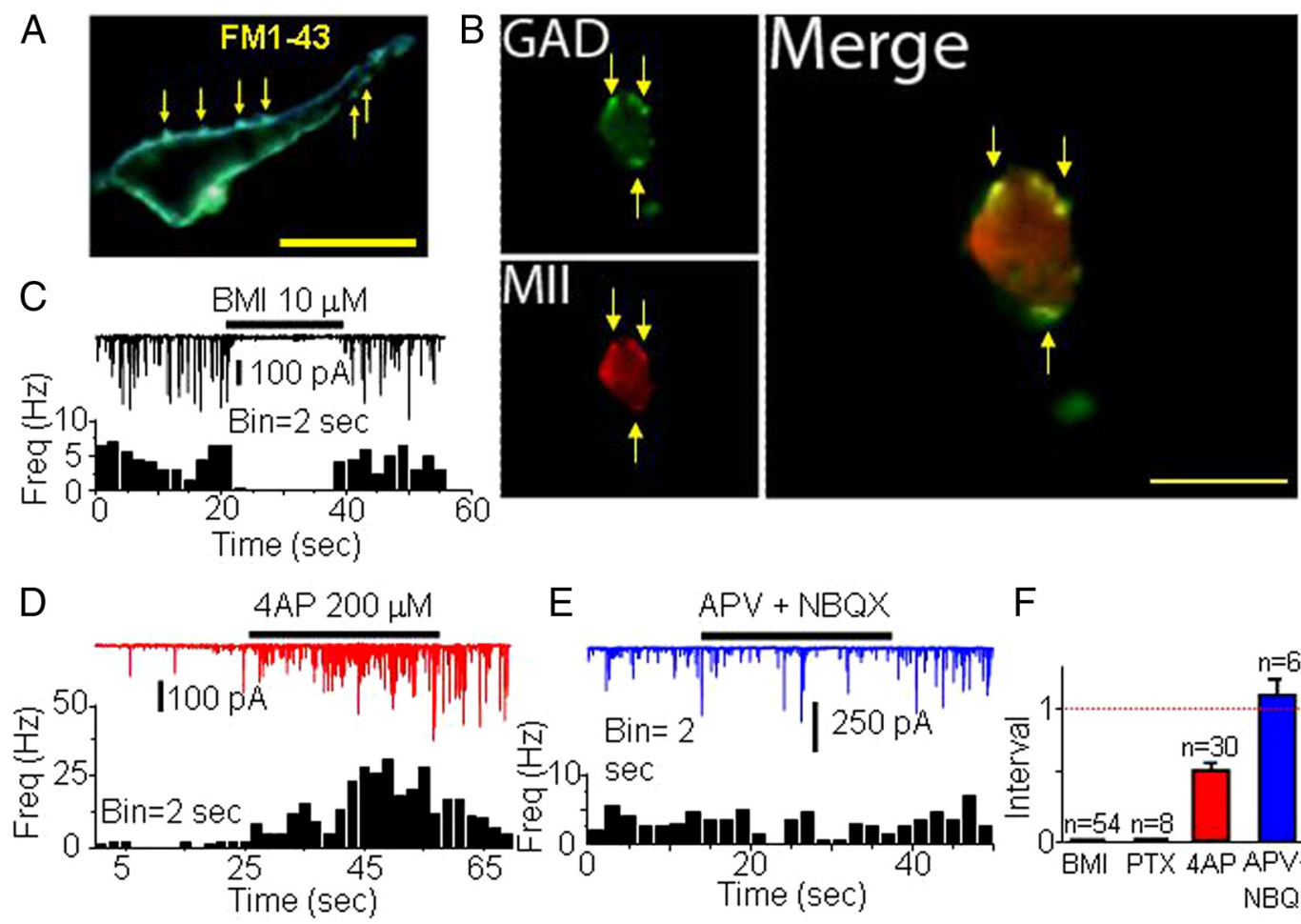

$\mathrm{E}$

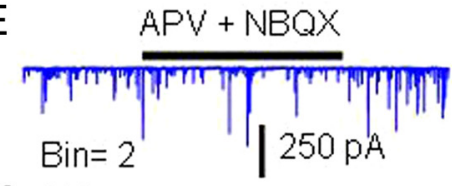

$\mathrm{F}$
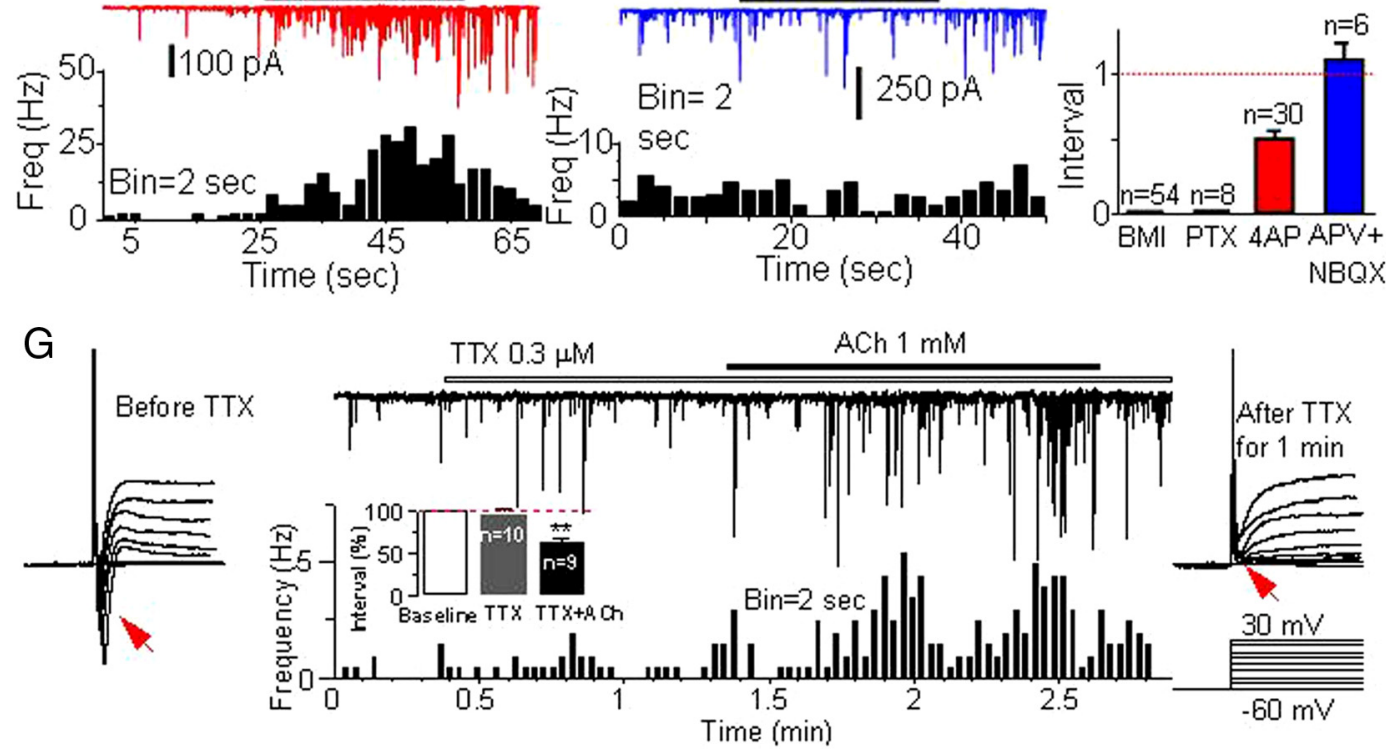

Figure 1. Initial evidence for the presence of presynaptic nAChR on GABAergic boutons apposed to single DA neurons mechanically dissociated from the rat VTA. FM 1-43 staining identified attached presynaptic boutons (indicated by yellow arrows) on a single neuron maintained after pure mechanical dissociation from the rat VTA (A). Anti-GAD65/67 immunostaining of a dissociated VTA neuron revealed positive labeling as large puncta (yellow arrows) attached to the surface of another acutely dissociated VTA neuron, indicating the presence of GABAergic presynaptic boutons (B) apposed to an otherwise unstained, non-GABAergic neuron. The same neuron also exhibited positive fluorescence labeling linked to biotinylated $\alpha$-Ctx MII also appearing as large puncta (yellow arrows) ( $\boldsymbol{B}$, bottom left). The same large puncta on the neuron were double labeled by GAD and $\alpha$-Ctx MII, as evident in the merged image (B, right), showing that there are $\alpha$-Ctx MII-sensitive nAChRs located on GABAergic presynaptic boutons. Similar dual labeling of GABA- and $\alpha$-Ctx MII-positive boutons has been obtained in six other neurons dissociated from three rats, but none of which were positive for conotoxin labeling (Sup. Fig. 3). Using whole-cell patch-clamp recording (in voltage-clamp mode), sporadically occurring mIPSCs were observed at a holding potential of $-60 \mathrm{mV}$. These mIPSCs were completely abolished by application of a GABA $A_{A}$ receptor antagonist, BMI (C; $\left.p<0.001, n=54\right)$, were significantly enhanced by application of 4-AP $(\boldsymbol{D} ; p<0.001$, $n=30$ ) but were not affected by exposure to ionotropic glutamate receptor antagonists (APV at $50 \mu \mathrm{m}$ plus NBQX at $20 \mu \mathrm{m})(\boldsymbol{E} ; p>0.05, n=6$ ). $\boldsymbol{F}$, Summary of effects of agents seen in $\boldsymbol{C}-\boldsymbol{E}$ on the frequency of mIPSCs. Data are means \pm SEM. The traces in $\boldsymbol{C}-\boldsymbol{E}$ were recorded from different neurons. Scale bars, $30 \mu \mathrm{m}$. PTX, Picrotoxin. $\boldsymbol{G}$, ACh potentiates GABAergic mIPSCS on VTA DA neurons in the presence of TTX $(0.3 \mu \mathrm{m})$ at a concentration adequate to block voltage-gated sodium currents [red arrows in traces on the left (before TTX exposure) and on the right (after TTX exposure)]. The frequency of mIPSCs that is insensitive to TTX exposure increases in the presence of $1 \mathrm{~mm}$ ACh (top middle, recording trace; bottom middle, mIPSC frequency histogram). Inset, A summary of results from $9-10$ neurons tested showing no effect on mIPSC frequency in the presence of TTX alone but an increase in the additional presence of $A C h .{ }^{* *} p<0.01$.

and washout (using a computer-controlled U-tube drug application system in these studies), (2) the ability to choose an appropriate age range of animals, (3) ease when identifying neuronal phenotype, and (4) decreased space-clamp problems during patch-clamp recordings. However, as for any in vitro preparations, the mechanically dissociated neuron model also has some limitations, notably, a lack of intact synaptic innervation (and thus the possibility of studying action potential-dependent mechanisms of neurotransmitter release) and a profound loss of distal processes (which frequently bear glutamatergic boutons).

The identification of a DA phenotype in bouton-adherent VTA neurons was performed as described previously (supple- mental Fig. 1, available at www.jneurosci.org as supplemental material) (Wu et al., 2004; Yang et al., 2009a). Functional presynaptic boutons were evident on the surface of mechanically dissociated, single DA neurons, as visualized via strong staining with FM 1-43 occurring as large puncta (Fig. 1A) (supplemental Fig. $2 A$, available at www.jneurosci.org as supplemental material) (Akaike and Moorhouse, 2003). We doubly labeled boutoncontaining DA neurons using biotinylated $\alpha$-Ctx MII and antiGAD65/67, the latter as a marker for GABAergic boutons. Most DA neurons were associated with boutons that exhibited positive, punctuate staining for both markers (Fig. $1 B$ ). Punctuate staining of $\alpha$-Ctx MII and anti-GAD65/67 frequently overlapped, in- 
dicating extensive colocalization on presynaptic boutons. Cells used in control experiments without biotinylated $\alpha$-Ctx MII or primary antibody showed no staining (data not shown). These results demonstrate that there are $\alpha$-Ctx MII-labeled nAChRs naturally expressed on the GABAergic presynaptic boutons adherent to VTA DA neurons. Similar staining results were obtained in six neurons dissociated from three rats. As an additional control, we repeated this experiment using cells isolated via a combination of enzymatic and mechanical dissociation, which removes presynaptic boutons from the VTA neurons. The results show that there were no puncta based on labeling with either biotinylated $\alpha$-Ctx MII or anti-GAD65/67 associated with VTA DA neuronal somata (supplemental Fig. $2 B$, available at www. jneurosci.org as supplemental material). In both preparations, we also observed weaker, diffuse staining of the cell body linked to $\alpha$-Ctx MII staining (Fig. 1 B) but also to FM 1-43 (supplemental Fig. 2, available at www.jneurosci.org as supplemental material). Because the labeling protocols involve cell permeabilization, biotinylated $\alpha$-Ctx MII is able to access the cell interior. Accordingly, the diffuse labeling of the cell body could reflect labeling of $\alpha 6^{*}$-nAChRs in an intracellular pool rather than functional $\alpha 6^{*}-$ nAChRs on the surface of DA neuronal soma.

To ask whether local, VTA, GABAergic neurons express any $\alpha 6^{*}$-nAChRs, we double-labeled dissociated VTA neurons with biotinylated $\alpha$-Ctx MII and anti-GAD65/67. As shown in supplemental Figure 3 (available at www.jneurosci.org as supplemental material), the GABAergic neurons exhibited strong, positive reaction to anti-GAD 65/67 (green) in all seven test neurons. However, only one (of seven tested cells) was colabeled with biotinylated $\alpha$-Ctx MII, suggesting relatively sparse (although detectable) expression of $\alpha 6^{\star}$-nAChRs in GABAergic neurons, consistent with a previous report (Klink et al., 2001).

\section{Miniature postsynaptic currents in acutely dissociated bouton-adherent VTA DA neurons}

Under voltage-clamp recording conditions, a total of 214 rat VTA DA neurons (mechanically dissociated from 150 rats) prepared under conditions that would preserve the presence of presynaptic boutons were tested. Small, sporadically occurring postsynaptic currents were recorded in 79\% (169 of 214) of these neurons at a holding potential of $-60 \mathrm{mV}$ (Fig. 1C). These synaptic currents were completely and reversibly abolished by application of either $10 \mu \mathrm{M}$ bicuculline or $100 \mu \mathrm{M}$ picrotoxin, $\mathrm{GABA}_{\mathrm{A}}$ receptorselective antagonists ( $p<0.001$; bicuculline vs baseline, $n=54$ or picrotoxin vs baseline, $n=8$ ) (Fig. $1 C, F$ ) but were not sensitive to the presence of ionotropic glutamate receptor antagonists NBQX $(20 \mu \mathrm{M})$ plus APV $(50 \mu \mathrm{M})$ (interevent interval was $114.2 \pm 13.8 \%$ of baseline, $p>0.05, n=6$ ) (Fig. $1 E, F)$. Currents also were not sensitive to the presence of the voltage-gated $\mathrm{Na}^{+}$ channel blocker TTX $(0.3 \mu \mathrm{M})$ (interevent interval was $97.9 \pm$ $6.1 \%$ of baseline, $p>0.05, n=10$ ), although the same concentration of TTX blocked $\mathrm{Na}^{+}$currents (Fig. 1G). Thus, the observed currents can be classified as mIPSCs and are attributable to responses on VTA DA neuronal $\mathrm{GABA}_{\mathrm{A}}$ receptors located on neuronal soma or proximal dendrites. 4-AP $(200 \mu \mathrm{M})$, a voltagegated potassium channel blocker that can potentiate neurotransmitter release, dramatically reduced the interevent interval of mIPSCs to $51.7 \pm 3.2 \%$ of baseline $(p<0.001, n=30)$ (Fig. $1 D, F)$, suggesting that these mIPSCs are the result of presynaptic GABA release from adherent boutons (Doi et al., 2002).

\section{ACh elicits an increase in the frequency of mIPSCs in VTA DA neurons independently of $\alpha 4 \beta 2-n A C h R s$ and $\alpha 7-n A C h R s$}

Based on our previous finding that $\alpha$-Ctx MII-sensitive nAChRs are expressed on GABAergic presynaptic boutons adherent to VTA DA neurons (Yang et al., 2009a), we investigated further which nAChR subtypes exist on GABAergic boutons and whether they mediate cholinergic modulation of GABA release. To fully activate all of the functional nAChR subtypes present, high concentrations of nAChR agonists were rapidly delivered. Under these experimental conditions, $1 \mathrm{~mm}$ ACh exposure often elicited postsynaptic whole-cell currents (Fig. 2, arrows), shown in our previous studies to be mediated by a diverse collection of VTA DA neuronal somatodendritic nAChRs (Fig. 2), but none of which was sensitive to the $\alpha 6^{*}-\mathrm{nAChR}$ antagonist $\alpha$-Ctx MII (Yang et al., 2009a). Especially evident in VTA DA neurons not having a large whole-cell current response mediated by somatodendritic nAChR, but also clear whenever the initial postsynaptic $\mathrm{nAChR}$ response desensitized, exposure to $1 \mathrm{~mm}$ ACh also significantly increased the frequency but not amplitude of mIPSCs (supplemental Fig. 4, available at www.jneurosci.org as supplemental material). In 93 neurons tested, the interevent interval was $50.2 \pm 2.0 \%$ of baseline ( $p<0.01, n=93)$ after exposure to $1 \mathrm{~mm}$ ACh, suggesting that ACh increases presynaptic GABA release onto bouton-adherent VTA DA neurons (Fig. $2 A a, B$ ). However, application of neither an $\alpha 4 \beta 2$-nAChR-selective agonist (0.1 mm RJR-2403) (Papke et al., 2000) nor an $\alpha 7$-nAChRselective agonist (10 mM choline) (Alkondon et al., 1997) increased the frequency of mIPSCs in most tested neurons. The interevent interval after RJR-2403 exposure was $98.9 \pm 4.0 \%$ of baseline ( $p>0.05, n=48)$ (Fig. $2 A b, B)$ and after choline application was $102.1 \pm 4.7 \%$ of baseline $(p>0.05, n=60)$ (Fig. $2 A c, B)$. Across a broader total 169 neurons tested, 128 neurons (76\%) responded to $1 \mathrm{~mm}$ ACh (exhibited as an increase in mIPSC frequency) (Fig. 3). Of these, 89 of 128 neurons (70\%) only responded to ACh (but not RJR-2403 or choline) with an increase in mIPSC frequency. In 26 of 128 neurons (20\%), both ACh and RJR-2043 increased mIPSC frequency, whereas in 8 of 128 neurons (6\%), both ACh and choline increased mIPSC frequency. Only 5 of 128 neurons (4\%) responded to all agonists, namely, ACh, RJR-2403, and choline, with increased mIPSC frequency (Fig. 3). These results indicate that, in a majority of cases, ACh increased mIPSC frequency on VTA DA neurons, but its actions were not attributable to effects on presynaptic $\alpha 4 \beta 2$ nAChRs or $\alpha 7-$ nAChRs on GABAergic boutons.

To further assess this notion, we also tested the effects of $\alpha 4 \beta 2-\mathrm{nAChR}$ and $\alpha 7-\mathrm{nAChR}$ antagonists on ACh-mediated changes in mIPSC frequency on the VTA DA neurons that responded only to ACh. After evoking an increase in mIPSC frequency with $1 \mathrm{~mm} \mathrm{ACh}$ (interevent interval was $53.4 \pm 3.0 \%$ of baseline, $p<0.01, n=7$ ) (Fig. $2 C a, D, E$ ), the same cell was pretreated (4 min) with either $1 \mu \mathrm{M} \mathrm{DH} \beta \mathrm{E}$, a relatively selective $\alpha 4^{*}-\mathrm{nAChR}$ antagonist (Harvey and Luetje, 1996; Harvey et al., 1996), or 10 nM MLA, a relatively selective $\alpha 7-\mathrm{nAChR}$ antagonist (Alkondon et al., 1992). Subsequently, the same neuron was challenged with ACh plus $\mathrm{DH} \beta \mathrm{E}$ or MLA while recording mIPSCs. We found that neither $1 \mu \mathrm{M}$ DH $\beta$ E (Fig. $2 A d$ ) nor $10 \mathrm{nM}$ MLA (Fig. $2 \mathrm{Ae}$ ) had any significant effect on the ACh-induced increase in mIPSC frequency (Fig. 2C,D). Statistical analysis showed that, with $\mathrm{DH} \beta \mathrm{E}$ pretreatment, $\mathrm{ACh}$ (plus $\mathrm{DH} \beta \mathrm{E}$ ) reduced the interevent interval to $51.7 \pm 9.5 \%(p<0.01, n=7)$, and, with MLA pretreatment, ACh (plus MLA) reduced the interevent interval to $59.3 \pm 8.1 \%(p<0.01, n=7)$, respectively. No significant differ- 
ence was found in interevent intervals among these two groups and the previously measured ACh-alone control $\left(F_{(2,18)}=\right.$ $0.27, p=0.8$, ANOVA). Collectively, these results suggest that $\mathrm{ACh}$-induced GABA release onto DA neurons in the VTA is mainly mediated through a subtype of $\mathrm{nAChR}$ distinct from $\alpha 4 \beta 2-$ nAChRs or $\alpha 7-$ nAChRs.

Although $\mathrm{DH} \beta \mathrm{E}$ failed to affect the ACh-induced increase in mIPSC frequency, it inhibited ACh-induced postsynaptic whole-cell currents in the mechanically dissociated neurons (Fig. $2 A d$ ). Of the 19 neurons tested, $\mathrm{DH} \beta \mathrm{E}$ ( 4 min pretreatment at 1 $\mu \mathrm{M})$ completely abolished postsynaptic responses in 10 neurons, and, in the remaining nine neurons, $\mathrm{DH} \beta \mathrm{E}$ showed inhibitory effects of $25-95 \%$. The mean inhibition was $85.4 \pm 5.3 \%(n=19, p<0.001)$, which is similar to our previously reported results on effects of $\mathrm{DH} \beta \mathrm{E}$ on ACh-induced wholecell currents in VTA DA neuronal somata (Yang et al., 2009a). The simplest explanation for the range of $\mathrm{DH} \beta \mathrm{E}$ effects on $\mathrm{ACh}$ induced somatic currents in dissociated VTA DA neurons is that this neuronal population expresses multiple nAChR subtypes, with $\alpha 4 \beta 2-\mathrm{nAChR}$ predominating. Indeed, we have previously demonstrated such diversity (Yang et al., 2009a).

\section{ACh modulates mIPSCs in VTA DA neurons through the activation of presynaptic $\alpha 6^{*}-$ nAChRs}

The preceding results raised the question of which non- $\alpha 4 \beta 2$, non- $\alpha 7-$ nAChR subtype is responsible for the ACh-induced increase in mIPSC frequency in VTA DA neurons. In light of the immunocytochemistry results indicating the presence of $\alpha$-Ctx MII-binding $\mathrm{nAChRs}$ on GABAergic boutons, we tested the effects of $\alpha$-Ctx MII, a relatively selective $\alpha 6 \beta 2^{*}-\mathrm{nAChR}$ blocker (McIntosh et al., 2004) on ACh-induced increases in mIPSC frequency. As shown in Figure 4A, 1 $\mathrm{mM}$ ACh increased the frequency of mIPSCs (interevent interval was $41.5 \pm 4.1 \%$ of baseline, $p<0.01, n=8$ ) (Fig. $4 A a$ ), and the effect was abolished by $10 \mathrm{nM} \alpha$-Ctx MII after a 4 min pretreatment (after $\alpha$-Ctx MII, the interevent interval was $104.8 \pm 6.8 \%$ of baseline, $p<0.01, n=8$ ) (Fig. $4 A b$ ). Figure $4 B$ compares the normalized interevent interval before and after ACh exposure (Fig. $4 \mathrm{Ba})$ or before and after ACh plus $\alpha$-Ctx MII exposure (Fig. $4 B b$ ), and it demonstrates that $\alpha$-Ctx MII prevented the AChinduced reduction of the interevent interval. Then, we examined the effects of a lower $\alpha$-Ctx MII concentration ( $1 \mathrm{nM}$ ) and found similar effects. Figure $4 C$ summarizes the effects of different concentrations of $\alpha$-Ctx MII on the ACh-induced
A
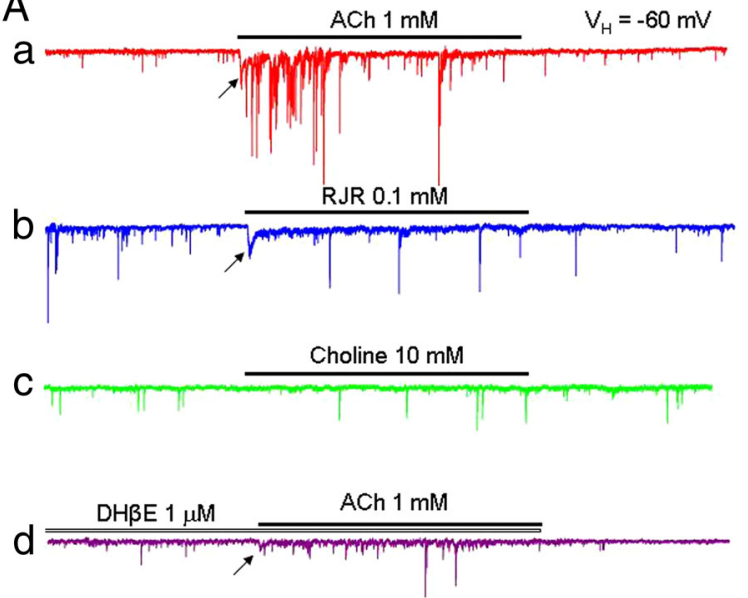

C
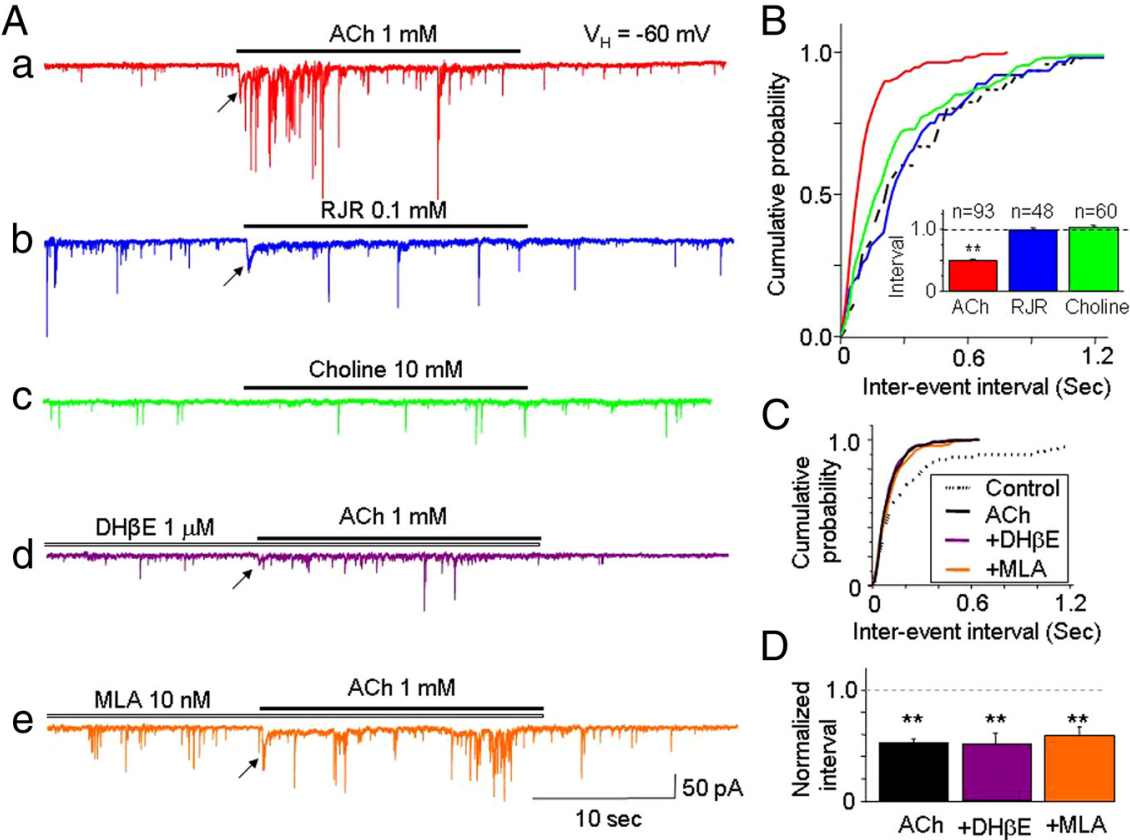

Figure 2. Pharmacological characterization of the ACh-induced increase in mIPSC frequency. $\boldsymbol{A}$, In a dissociated VTA neuron, application of $1 \mathrm{~mm}$ ACh significantly enhanced mIPSCS (and also induced a small, transient, inward, whole-cell current in this cell;

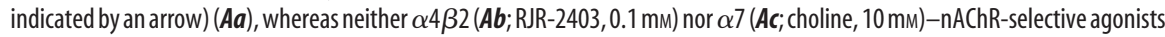
had any significant effect. In the same neuron, the ACh-induced increase in mIPSCs was not affected by either $\alpha 4 \beta 2$ (Ad; DH $\beta$, $1 \mu \mathrm{M}$ ) or $\alpha 7$ (Ae; MLA, $10 \mathrm{~nm})$-nAChR-selective antagonists after 4 min pretreatments. However, DH $\beta$ E did clearly suppress the postsynaptic, inward, whole-cell current $(\boldsymbol{A d})$ also elicited by RJR-2403 $(\boldsymbol{A b})$ but insensitive to MLA. $\boldsymbol{B}$, Summary of effects of nicotinic agonists on ACh-induced mIPSC interevent intervals. Inset, Changes in the normalized average interevent interval of mIPSCs induced by different agonists. The horizontal dashed line presents a baseline level (as 100\%) of mIPSCs before agonist exposure. $\boldsymbol{C}, \boldsymbol{D}$, Summaries of effects of $\mathrm{DH} \beta \mathrm{E}$ and MLA on ACh-induced increases in mIPSC frequency are shown (normalized average antagonist effects from 7 neurons tested). ${ }^{* *} p<0.01$.

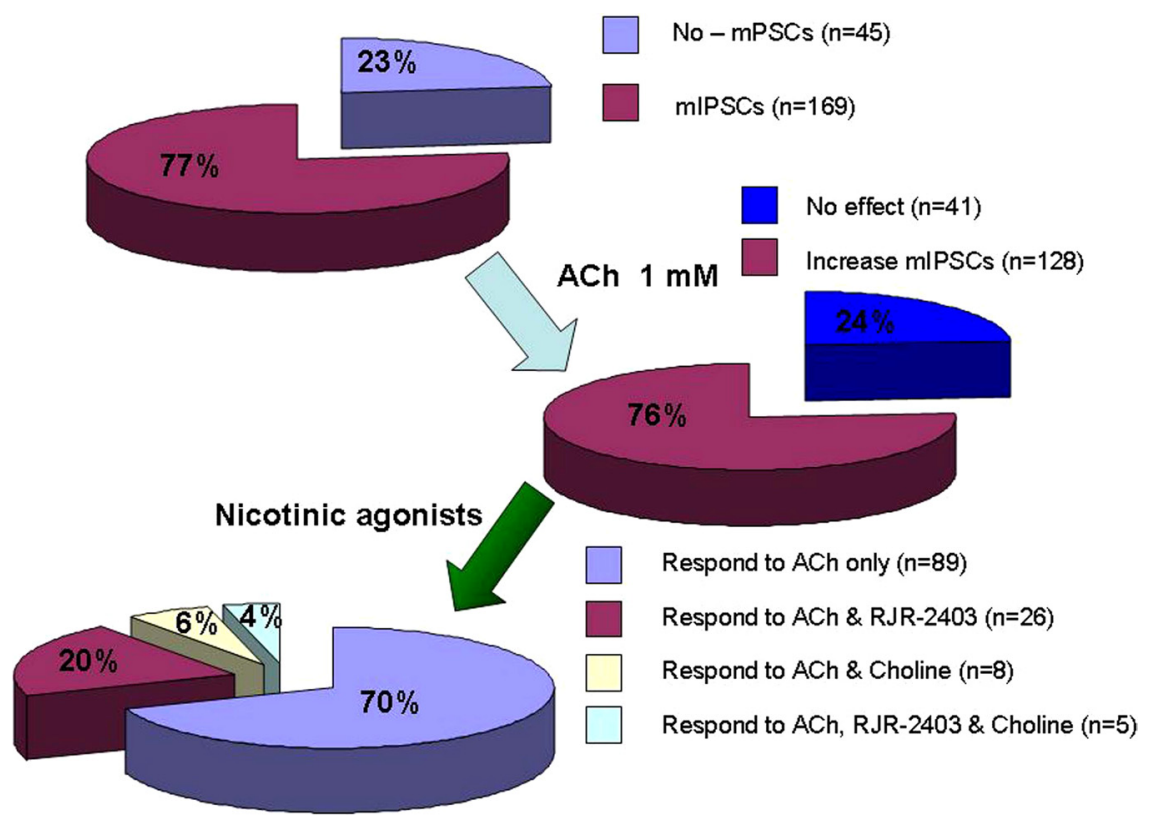

Figure 3. Summary of the distribution of VTA DA neurons displaying ACh-induced increases in mIPSC frequency. In total, recordings were made from 214 VTA DA neurons isolated from 150 rats. Patch-clamp recordings showed that $77 \%$ (169 of 214) of the dissociated neurons exhibited mIPSCs. Application of $1 \mathrm{~mm}$ ACh induced an increase in mIPSC frequency in $76 \%$ (128 of 169) of mIPSC-positive neurons. This group of neurons (ACh-responsive) was further tested with $\alpha 4 \beta 2-\mathrm{nAChR}$ - and $\alpha 7-\mathrm{nAChR}-$ selective agonists (RJR-2403 and choline). The results demonstrate that 70\% of dissociated VTA DA neurons having ACh-induced increases in mIPSCs failed to respond similarly to the $\alpha 4 \beta 2-n A C h R$-selective agonist RJR-2403 or to the $\alpha 7-n A C h R$-selective agonist choline. 
A
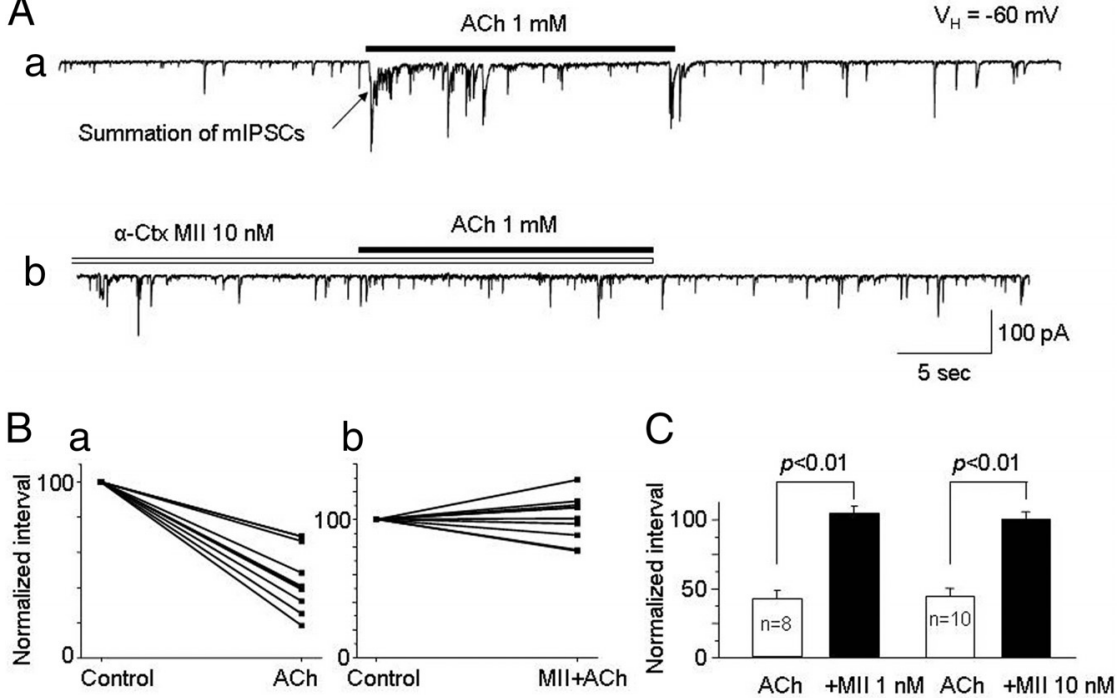

Figure 4. Effects of the $\alpha 6$-nAChR antagonist $\alpha$-Ctx Mll on the ACh-induced increase in mIPSC frequency. $\boldsymbol{A}$, Representative typical trace from an acutely dissociated VTA DA neuron $(\boldsymbol{A a})$ and the effect of $10 \mathrm{~nm} \alpha$-Ctx MII $(\boldsymbol{A} \boldsymbol{b})$ on the ACh-induced increase in mIPSCs. A recorded neuron was pretreated with $\alpha$-Ctx MII for 4 min, which was then coapplied with 1 mm ACh. $B$, Comparison of normalized interevent intervals before and after ACh exposure (Ba) and before and after ACh plus $\alpha$-Ctx MII ( 4 min pretreatment) exposure (Bb). C, Bar graphs summarize the effect of $\alpha$-Ctx MII (1 and $10 \mathrm{~nm}$ ) on the ACh-induced increase in mIPSCs and show that both 1 and $10 \mathrm{~nm} \alpha$-Ctx MII significantly ( ${ }^{* *} p<0.01$ ) reduced (in fact, prevented) the ACh-induced increase in mIPSC frequency (as measured by a reduced interevent interval). Early after exposure to $A C h$, the recording trace shows summation of $\operatorname{mIPSCS}(\boldsymbol{A a})$.

reduction of the interevent interval of mIPSCs and shows that $\alpha$-Ctx MII prevented the effects of ACh (interevent interval of $41.5 \pm 4.1$ vs $104.8 \pm 6.8 \%$ of baseline for ACh vs ACh plus $\alpha$-Ctx MII at $1 \mathrm{nM}, p<0.01, n=8$; and interevent interval of $44.7 \pm 6.8$ vs $101.2 \pm 5.1 \%$ of baseline for ACh vs ACh plus $\alpha$-Ctx MII at 10 $\mathrm{nM}, p<0.01, n=10)$. In these tested neurons, $\mathrm{DH} \beta \mathrm{E}(1 \mu \mathrm{M})$ and MLA (10 nM) also were examined using the same protocol (4 min pretreatment) but did not have an effect on the ACh-induced reduction of the interevent interval (data not shown, but see the results in the preceding sections). At the concentrations used in the present study, DH $\beta E$ and MLA would be expected to have weak to no effects on $\alpha 6 \beta 2^{\star}$-nAChRs (Mogg et al., 2002; Salminen et al., 2007). Together, these results suggest that functional $\alpha 6^{*}$-nAChRs located on GABAergic boutons are predominantly responsible for ACh-induced GABA release onto DA neurons in the VTA.

In view of the observation that $\alpha$-Ctx MII also blocks $\alpha 3 \beta 2-$ nAChRs (Cartier et al., 1996) (for review, see Yang et al., 2009b), we tested the effect of $1 \mathrm{~nm} \alpha$-Ctx PIA, a more selective antagonist for $\alpha 6^{*}$-nAChRs (Dowell et al., 2003), on the ACh-induced increase in mIPSC frequency. As shown in Figure $5 A a$, application of $1 \mathrm{~mm}$ ACh decreased the interevent interval to $50.9 \pm 6.2 \%$ of baseline ( $p<0.01, n=7)$, and pretreatment with $1 \mathrm{nM} \alpha$-Ctx PIA for 4 min abolished the effect of ACh (interevent interval was $98.9 \pm 5.9 \%$ of baseline for ACh vs $\alpha$-Ctx PIA plus ACh, $p<0.01$, $n=7$ ) (Fig. $5 A b$ ). After a 5 min washout, the ACh-induced increase in mIPSC frequency partially recovered (Fig. 5Ac). Again, there were no effects of $\mathrm{DH} \beta \mathrm{E}(1 \mu \mathrm{M})$ or MLA $(10 \mathrm{nM})$ on the ACh-induced increase in mIPSC frequency in the same tested neurons (data not shown). Figure $5 B$ compares the relationship of cumulative probability and interevent interval and shows that $\mathrm{ACh}$ reduced the interevent interval (Fig. $5 \mathrm{C}$ ). Analysis of the effects of $\alpha$-Ctx MII or $\alpha$-Ctx PIA alone on baseline mIPSCs (without agonist stimulation) showed that neither of these com- pounds affected baseline mIPSC frequency (supplemental Fig. 5, available at www.jneurosci.org as supplemental material). Together, these results show that, in VTA DA neurons, both $\alpha$-Ctx MII ( 1 or $10 \mathrm{~nm})$ and $\alpha$-Ctx PIA (1 nM) prevent ACh-induced increases in mIPSC frequency but have no effect on baseline mIPSC frequency. Thus, our data demonstrate that functional $\alpha 6^{*}-\mathrm{nAChRs}$ are located on presynaptic boutons, in which they mediate an increase in ACh-induced GABA release onto DA neurons in the VTA.

Using VTA slices, we were not able to demonstrate a consistent, nicotinic agonist modulation of presynaptic GABA release, manifest as changes in mIPSCs, although we did sometimes see effects mimicking those seen using acutely dissociated neurons (data not shown). This limited our ability to efficiently perform detailed pharmacological experiments to characterize such nicotinic effects in the slice preparations. In brain slices, the slow drug diffusion times may lead to desensitization of $\mathrm{nAChR}$ occurring without activation. This reinforces the point that our chosen bouton-containing dissociated neuron preparation is the best available model for the present study of presynaptic nAChR pharmacology.

In the experiments with bouton-adherent VTA DA cell preparations from rats or mice, it initially appeared that $\alpha$-Ctx PIA also reduced what could be taken as an ACh-induced, somatic nAChR-mediated whole-cell current response (Figs. 4-6). However, additional experiments showed that the $\mathrm{GABA}_{\mathrm{A}}$ receptor antagonist bicuculline $(10 \mu \mathrm{M})$ abolished these responses, demonstrating that they are mediated by $\mathrm{GABA}_{\mathrm{A}}$ receptors (data not shown). Thus, the $\alpha$-Ctx PIA sensitivity of the large inward current response to $\mathrm{ACh}$ reflected inhibition of $\mathrm{ACh}$-induced GABA release that sometimes was large enough to cause summation of mIPSCs. Additional studies using 4-AP indicate that this agent also can elicit mIPSC summation (data not shown). Thus, we still have no evidence for somatic $\alpha 6^{*}-\mathrm{nAChR}$ sensitive to conotoxins PIA or MII on VTA DA neurons, in contrast to the clear evidence for their presynaptic GABA terminal localization.

Under conditions in which bicuculline or $\alpha$-Ctx PIA reduced mIPSC frequency, ACh-induced postsynaptic whole-cell inward currents in neurons isolated using enzymatic/mechanical dissociation (with no associated presynaptic boutons) were unaffected by treatment with bicuculline $(92.3 \pm 3.8 \%$ of control, ACh plus BMI vs ACh, $p=0.09, n=7)$ or $\alpha$-Ctx PIA (102.3 $\pm 8.6 \%$ of control, ACh plus PIA vs ACh, $p=0.9, n=6$ ). These data strongly indicate that $\alpha$-Ctx PIA affects presynaptic nAChR modulating GABA release rather than postsynaptic currents elicited by ACh.

\section{Studies using nAChR $\beta 2$ subunit-null mice demonstrate that the $\mathrm{nAChR} \boldsymbol{\beta} 2$ subunit is an indispensable component of functional, presynaptic $\alpha 6^{\star}-\mathrm{nAChRs}$}

To examine further the subunit composition of the GABAbouton-associated, functional, presynaptic $\alpha 6^{*}-\mathrm{nAChR}$ population, we assessed ACh-induced increases in mIPSC frequency in both WT and nAChR $\beta 2$ subunit KO mice, which were the only 
mice used in this study (all other data were collected from rats). Comparisons between DA neurons prepared from $\mathrm{nAChR}$ $\beta 2 \mathrm{KO}$ or WT mice showed that, in resting conditions (e.g., not stimulated by agonist), there were no significant differences in mIPSC frequency and amplitude (supplemental Fig. 6, available at www. jneurosci.org as supplemental material). For WT mice, $1 \mathrm{~mm}$ ACh decreased the interevent interval of mIPSCs to $50.1 \pm$ $5.2 \%$ of baseline $(p<0.001, n=10)$ (Fig. $6 \mathrm{Aa}$ ), and this ACh-induced effect was abolished by $1 \mathrm{~nm} \alpha$-Ctx PIA (interevent interval was $103.4 \pm 8.8 \%$ of baseline, ACh plus $\alpha$-Ctx PIA vs ACh, $p<0.01, n=$ 10) (Fig. 6Ab--Ad). These results closely match those obtained in rat preparations. In contrast, for $\beta 2 \mathrm{KO}$ mice, $1 \mathrm{~mm} \mathrm{ACh}$ failed to increase mIPSC frequency (interevent interval was $105.6 \pm 4.8 \%$ of baseline, $p>0.05, n=9$ ) (Fig. $6 B$ ) in nine of nine VTA DA neurons tested (dissociated from nine $\beta 2 \mathrm{KO}$ mice). These findings suggest that the nAChR $\beta 2$ subunit is essential for the formation of functional presynaptic $\alpha 6^{\star}-\mathrm{nAChRs}$.

\section{Presynaptic $\alpha 6^{\star}-$ nAChRs trigger calcium entry}

As additional support of our findings that ACh increased the frequency of mIPSCs through activation of presynaptic $\alpha 6^{*}$ nAChRs, we examined ACh-induced changes in $\left[\mathrm{Ca}^{2+}\right]_{\mathrm{i}}$ in individual, purified VTA nerve terminals (synaptosomes) using confocal microscopic imaging (Nayak et al., 2001). The results demonstrated that ACh (1 mM) markedly enhanced $\mathrm{Ca}^{2+}$ levels in individual, isolated VTA synaptosomes (Fig. 7). The $\alpha 6^{*}-$ nAChR antagonist $\alpha$-Ctx PIA (1 nM), but not the $\alpha 7^{\star}$-selective nAChR antagonist $\alpha$-BgTx (10 nM), eliminated ACh-induced $\mathrm{Ca}^{2+}$ mobilization (Fig. 7), further confirming the presence of functional $\alpha 6^{*}-$ nAChRs on presynaptic boutons in the VTA. After block of $\mathrm{Ca}^{2+}$ entry by $\alpha$-Ctx PIA, $30 \mathrm{~mm} \mathrm{~K}^{+}$still increased $\mathrm{Ca}^{2+}$ entry, suggesting that $\alpha$-Ctx PIA selectively blocked presynaptic $\alpha 6^{*}$-nAChR-mediated $\mathrm{Ca}^{2+}$ entry. These findings indicate that the presynaptic $\alpha 6^{\star}-\mathrm{nAChRs}$ located on GABAergic boutons of VTA DA neurons trigger significant $\mathrm{Ca}^{2+}$ influx, which, in turn, could trigger the observed GABA release.

\section{Effects of smoking-relevant concentrations of nicotine on $\alpha 6^{*}-\mathrm{nAChR}$ function}

Electrophysiological studies using brain-slice preparations have shown that nAChRs with different subunit compositions appear to exhibit different patterns of transient activation, followed by functional desensitization during subchronic nicotine exposure (3-10 $\mathrm{min}$ ) at concentrations similar to those found in the brains of human smokers (100-500 nM) (Pidoplichko et al., 1997; Wooltorton et al., 2003). We tested how presynaptic $\alpha 6^{*}$ nAChRs responded to nicotine exposure under our experimental conditions. Interestingly, acute exposure to a smoking-relevant concentration of nicotine (500 nM) for $20 \mathrm{~s}$ failed to increase mIPSCs in any tested neurons (interevent interval was $95.3 \pm$ $5.4 \%$ of baseline, $p>0.05, n=30$ ) (Fig. $8 A$ ). However, previous exposure to $500 \mathrm{~nm}$ nicotine for $4 \mathrm{~min}$ abolished $1 \mathrm{~mm}$ ACh-
B
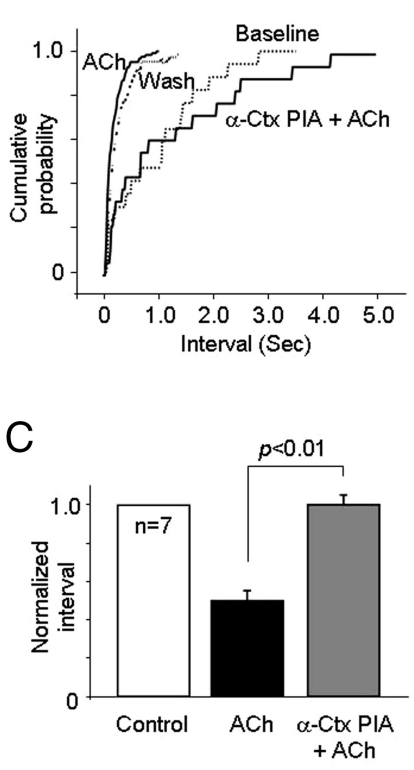
A
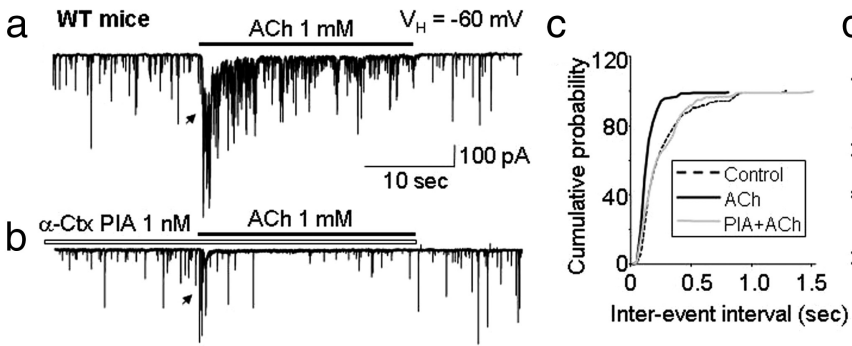

B

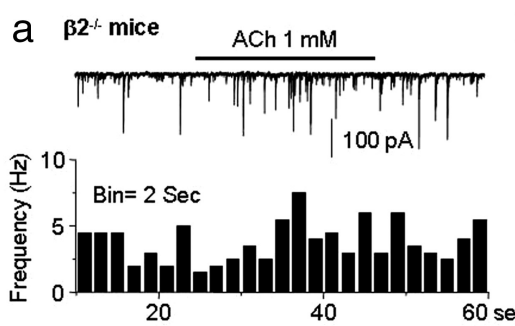

b

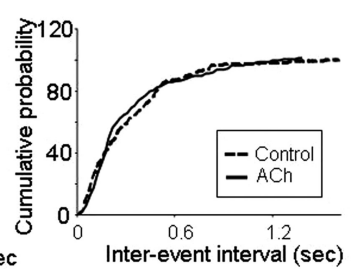

Figure 6. ACh-induced modulation of mIPSCs in VTA DA neurons dissociated from wild-type or $\beta 2^{-1-}$ mice. Traces in $A a$ and $\boldsymbol{A} \boldsymbol{b}$ were recorded from the same wild-type neuron. In $\boldsymbol{A} \boldsymbol{b}, \alpha$-Ctx PIA (1 nм) was preapplied for 4 min. Compared with control (baseline), the ACh-induced increase in mIPSCs was blocked by $1 \mathrm{~nm} \alpha$-Ctx PIA, as summarized in cumulative probability curves $(\boldsymbol{A c})$ and normalized average interevent interval analyses ( $\boldsymbol{A d})$. The arrows in $\boldsymbol{A} \boldsymbol{a}$ and $\boldsymbol{A} \boldsymbol{b}$ indicate the summation of mIPSCS. $\boldsymbol{B}$, The same experiments were repeated using $\beta 2^{-1-}$ mice, in which ACh failed to modulate mIPSCs $(B \boldsymbol{a})$ in nine tested DA neurons, as summarized in cumulative probability curves $(\boldsymbol{B} \boldsymbol{b})$ and normalized average interevent interval analyses $(\boldsymbol{B C})$. In these neurons, 4-AP enhanced mIPSCs (data not shown).

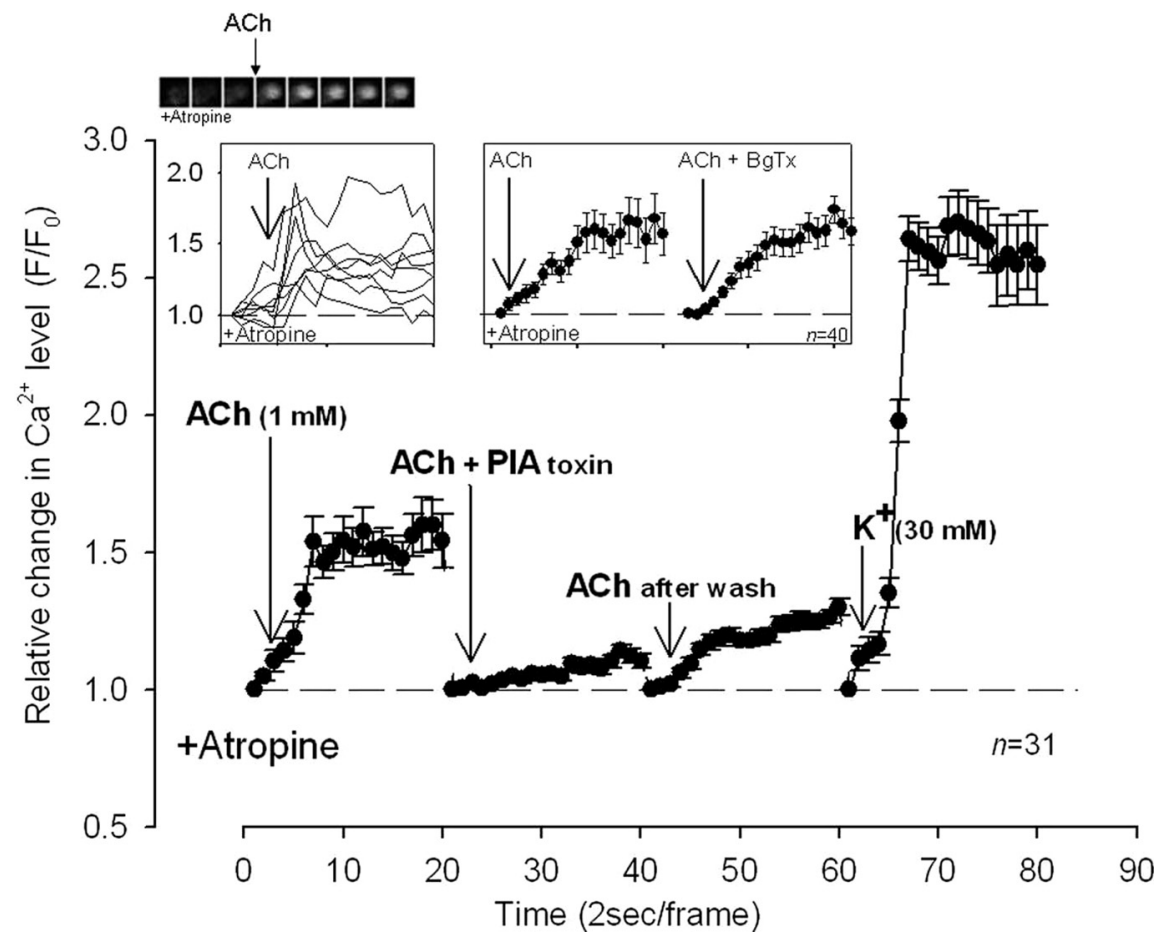

Figure 7. $\mathrm{Ca}^{2+}$ imaging of nicotinic responses in individual rat VTA synaptosomes using confocal microscopy. ACh (1 mm)induced responses in individual, Fluo-4-loaded synaptosomes preincubated with atropine $(0.5 \mu \mathrm{m})$ with or without nicotinic antagonist treatment ( $\alpha$-Ctx PIA at $1 \mathrm{~nm}$ or $\alpha$-BgTx at $50 \mathrm{~nm}$ ) were quantified using MetaMorph (representative image sequence shown in top left inset; 2 s/frame). Sustained $\mathrm{Ca}^{2+}$ responses were sensitive to $\alpha$-Ctx PIA but insensitive to $\alpha$-BgTx (see inset, right; 10 s/interval). A small subset of transient $\mathrm{Ca}^{2+}$ responses (see inset, left) were eliminated by $\alpha$-BgTx (not shown).

identified presynaptic $\alpha 6^{*}-$ nAChRs (Fig. 9B). Chronic exposure to the same concentrations of nicotine induced a biphasic response. Shortly (1 d) after stopping chronic nicotine administration, presynaptic GABA release in response to $\mathrm{ACh}$ was reduced compared with

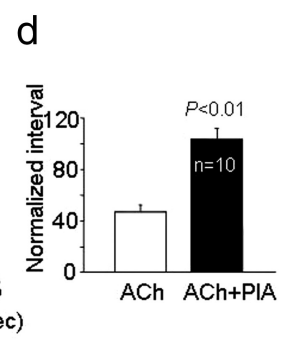

C

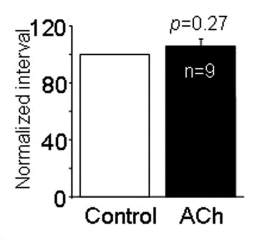

a no-drug control. After a longer recovery period, however, presynaptic GABA release in response to ACh was actually enhanced compared with the no-drug control.

\section{Discussion}

The central, novel finding in the present study is that functional $\alpha 6^{*}$-nAChRs are naturally expressed on GABAergic presynaptic boutons, in which they mediate cholinergic modulation of GABA release onto DA neurons in the VTA. Acute exposure to smoking-relevant concentrations of nicotine desensitizes, rather than activates, these presynaptic $\alpha 6^{*}-\mathrm{nAChRs}$ and eliminates cholinergic enhancement of GABA release. Chronic nicotine administration has biphasic effects on the same measure, initially suppressing (after $1 \mathrm{~d}$ of recovery) and then enhancing (after $5 \mathrm{~d}$ of recovery) ACh-induced enhancement of GABA release. These nicotineinduced modulations of GABA release would be expected to affect DA neuron activity in the VTA.

Functional $\alpha 6^{*}-\mathrm{nAChRs}$ are located presynaptically on GABAergic boutons adherent to VTA DA neurons

Cholinergic modulation of neurotransmitter release (Wonnacott, 1997; Keath et al., 2007) is thought to be important in the regulation of neural plasticity and in nicotine addiction (Mansvelder et al., 2002, 2006; Dani and Harris, 2005). In VTA slice preparations, previous work had indicated that $\alpha 4 \beta 2-\mathrm{nAChRs}$ are expressed on GABAergic terminals, in which they regulate GABA release (Mansvelder et al., 2002), whereas $\alpha 7$-nAChRs are expressed in glutamatergic terminals, in which they modulate glutamate release (Dani and De Biasi, 2001; Keath et al., 2007). In contrast, there is little information about the function of $\alpha 6^{*}-$ nAChRs in the VTA, despite notably dense expression of nAChR $\alpha 6$ subunits as mRNA in this region (Le Novère et al., 1996; Klink et al., 2001; Azam et al., 2002; Yang et al., 2009a). In particular, the extent to which VTA $\alpha 6^{*}$ nAChRs contribute to presynaptic control of neurotransmitter release onto VTA DA neurons or to postsynaptic alteration of excitability in those neurons has been unclear.

Here, we find that, in most boutonassociated VTA DA neurons tested, exposure to ACh enhances the frequency of TTX-insensitive mIPSCs blocked by $\mathrm{GABA}_{\mathrm{A}}$ receptor antagonists and mimicked by an agent that elevates neurotransmitter release. Neither RJR-2403 nor choline, selective agonists for $\alpha 4 \beta 2-\mathrm{nAChR}$ or $\alpha 7-\mathrm{nAChR}$, respectively, increase mIPSCs. ACh-stimulated in- 
creases in mIPSC frequency are reversibly abolished by a low concentration (1 nM) of $\alpha$-Ctx MII (Fig. 4) or $\alpha$-Ctx PIA (Fig. 5) but not by $\mathrm{DH} \beta \mathrm{E}$ or MLA (Fig. 2), which are selective for $\alpha 4 \beta 2-\mathrm{nAChR}$ or $\alpha 7-$ $\mathrm{nAChR}$, respectively. In addition, there is no ACh-stimulated increase in mIPSC frequency in animals lacking expression of nAChR $\beta 2$ subunits. Collectively, these electrophysiological, pharmacological, and genetic approaches indicate that GABA release from presynaptic boutons apposed to VTA DA neurons is modulated by $\alpha 6^{*}-$ nAChRs distinct from $\alpha 4 \beta 2-\mathrm{nAChR}$ and $\alpha 7-$ nAChRs.

The presynaptic localization of $\alpha 6^{*}$ nAChRs also is supported by evidence that $\alpha$-Ctx MII does not block whole-cell current responses on VTA DA neurons elicited by nicotinic agonists, which instead are mediated via other $\mathrm{nAChR}$ subtypes located on VTA DA neuronal soma and/or proximal dendrites (Yang et al., 2009a). Responses that could be taken as whole-cell currents actually reflect summation of GABAergic mIPSCs that are blocked by $\mathrm{GABA}_{\mathrm{A}}$ receptor antagonists, mimicked by 4-AP, and absent when neurons are dissociated using an enzymatic/mechanical method that removes presynaptic boutons. Colocalization of nerve terminal labeling, anti-GAD immunostaining, and $\alpha$-Ctx labeling also is consistent with presynaptic localization of $\alpha 6^{*}$-nAChRs. Moreover, neurochemical studies show that there is conotoxin-sensitive, but BgTx-insensitive, elevation in $\mathrm{Ca}^{2+}$ levels in VTA synaptosomes. Although we are not able to distinguish between GABAergic and glutamatergic boutons in VTA synaptosomal preparations, the conotoxinsensitive portion of the ACh-induced intracellular $\mathrm{Ca}^{2+}$ elevation is likely mediated through GABAergic boutons.

It is well established that presynaptic glutamatergic terminals/boutons predominantly express $\alpha 7-\mathrm{nAChRs}$ (Dani and De Biasi, 2001; Mansvelder and McGehee, 2002), but these boutons and receptors may have escaped detection in our physiological and neurochemical studies, perhaps being apposed to more distal dendrites on VTA DA neurons and/or being more fragile. However, the current data are entirely consistent with other evidence for $\alpha 6^{*}-\mathrm{nAChR}$ localization on presynaptic terminals of DA neurons and their important roles in modulation of DA release onto the nucleus accumbens (NAc) (Exley et al., 2008).

Although we are not able to determine the sources of VTA GABAergic presynaptic boutons in our preparation, we have provided preliminary evidence based on GAD immunostaining of some cells in our acutely dissociated preparations that at least some boutons may come from local (VTA) GABAergic interneu-

A

A

B a

C

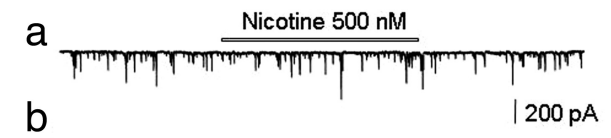

N $^{6}$.
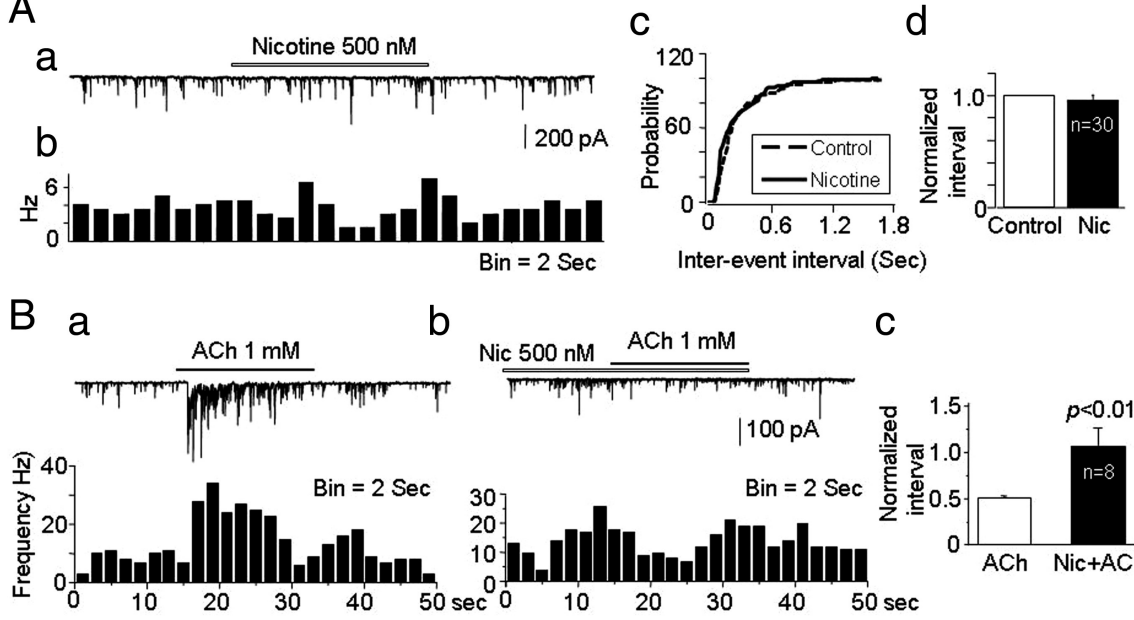

b

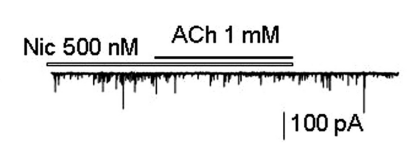

C

Figure 8. Effects of nicotine exposure on mIPSCs and their sensitivity to ACh. $A$, Representative trace of the effect of nicotine $(500 \mathrm{~nm})$ on mIPSCs $(\boldsymbol{A} \boldsymbol{a})$ with a corresponding time-frequency histogram $(\boldsymbol{A} \boldsymbol{b})$. Cumulative probability interevent interval relationships show no difference before and after nicotine exposure $(\boldsymbol{A c})$. In 30 neurons tested, $500 \mathrm{~nm}$ nicotine did not affect the frequency of mIPSCS ( $\boldsymbol{A} \boldsymbol{d})$. B, Representative traces and corresponding time-frequency histograms of the $A C h$-induced increase in mIPSCs under control conditions $(\boldsymbol{B} \boldsymbol{a})$ or after 4 min with $500 \mathrm{~nm}$ nicotine ( $\boldsymbol{B} \boldsymbol{b}$; Nic) show that nicotine preexposure abolishes the ACh effect in eight neurons tested ( $\boldsymbol{B C}$ ).
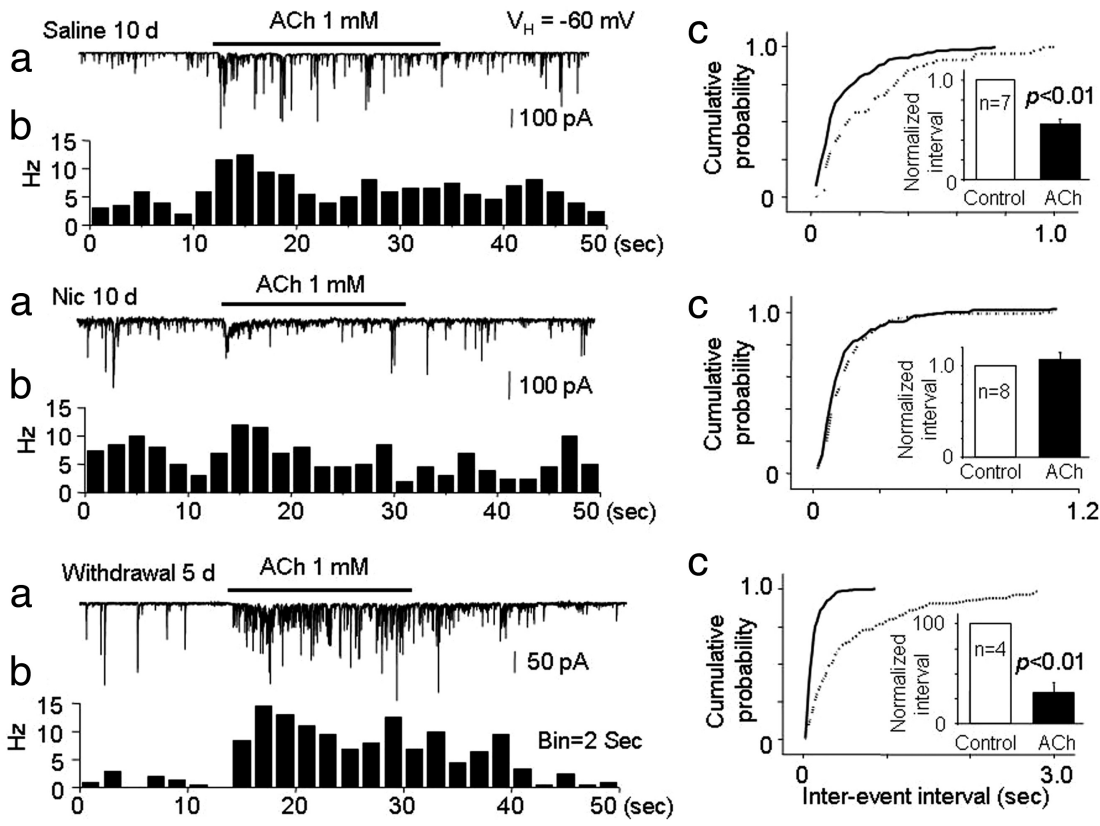

Figure 9. Effects of nicotine on mIPSCs and the ACh-induced increase in mIPSCs in VTA neurons isolated from rats subjected to chronic systemic injection of nicotine. Rats were injected with nicotine $(0.5 \mathrm{mg} / \mathrm{kg}$, i.p.) or saline (vehicle control) every day for $10 \mathrm{~d}$, and patch recording of isolated VTA neurons was performed on day 11. For the nicotine withdrawal group, patch recording of isolated VTA neurons was performed on day 16 . Representative typical traces and the corresponding time-frequency histograms of the ACh-induced change in mIPSCs in VTA neurons from rats treated with saline $(\boldsymbol{A})$, nicotine $(\boldsymbol{B})$, or nicotine followed by nicotine withdrawal for $5 \mathrm{~d}$ (C). Compared with mIPSCs in VTA neurons from saline-treated rats (AC), VTA neurons from rats chronically treated with nicotine displayed no increase in mIPSC frequency in response to $A C h(B \boldsymbol{C})$, with the response to $A C h$ rebounding in VTA neurons from rats after a $5 \mathrm{~d}$ withdrawal (Cc).

rons. Alternatively, GABAergic neurons in other brain regions such as NAc and ventral pallidum are known to innervate the VTA (Zahm, 1989; Heimer et al., 1991; Kalivas et al., 1993; Steffensen et al., 1998). Determining the precise source of these GABA terminals will require additional investigation. Regardless of the point of origin of the terminals, the regulation of GABA release through presynaptic $\alpha 6^{*}$-nAChRs seems very likely to 
play an important role in the regulation of VTA DA neuronal function.

\section{Subunit composition of presynaptic $\alpha 6^{*}-\mathrm{nAChRs}$}

High levels of nAChR $\alpha 6$ and $\beta 2$ subunit expression as message in the VTA (Yang et al., 2009a) are consistent with indications that functional $\alpha 6 \beta 2^{\star}-$ nAChRs are present in midbrain DA neurons (Champtiaux et al., 2003). The absence of conotoxin-sensitive, ACh-induced increases in mIPSC frequency in boutonassociated VTA DA neurons prepared from $\beta 2 \mathrm{KO}$ mice confirms that the $\mathrm{nAChR} \beta 2$ subunit is an indispensable component of $\alpha 6^{*}-\mathrm{nAChRs}$ on presynaptic GABAergic boutons. There also is a complete loss of $\alpha$-Ctx MII-sensitive DA release in VTA DA neuron terminal regions in $\beta 2 \mathrm{KO}$ mice (Salminen et al., 2004). Our data cannot completely exclude the presence of other $\alpha$ or $\beta$ subunits in functional $\alpha 6^{\star}-\mathrm{nAChRs}$ associated with VTA GABAergic boutons. However, our pharmacological experiments indicate that presynaptic nAChRs may not include the $\alpha 4$ subunit, because the responses were insensitive to RJR-2403 and $\mathrm{DH} \beta \mathrm{E}$. If true, this finding would be in contrast with previous studies reporting that functional $\alpha 6^{*}$-nAChRs located on DA neuronal somata contain the $\alpha 4$ subunit $[\alpha 4 \alpha 6 \alpha 5 \beta 2-\mathrm{nAChR}$ (Klink et al., 2001), $\alpha 4 \alpha 6 \beta 2^{*}-\mathrm{nAChR}$ (Champtiaux et al., 2003)]. Conversely, other studies suggest that $\mathrm{DH} \beta \mathrm{E}$ is not particularly potent at any $\alpha 6 \beta 2^{\star}-n A C h R$ subtype, including those that seem to contain $\alpha 4$ and/or $\beta 3$ subunits and that $\mathrm{DH} \beta \mathrm{E}$ at the concentration $(1 \mu \mathrm{M})$ used in the present study would be expected to have only marginal effects on $\alpha 6 \beta 2^{\star}$-nAChR function (Salminen et al., 2007; Grady et al., 2010). Perhaps as an example, the low sensitivity to $\mathrm{DH} \beta \mathrm{E}$-mediated blockade of postsynaptic nicotinic responses seen in some VTA DA neurons could reflect functional expression of $\alpha 4 \beta 2^{*}-\mathrm{nAChR}$ also containing additional subunits. $\mathrm{DH} \beta \mathrm{E}$ is thought to act at the interface between $\alpha 4$ and $\beta 2$ subunits (Exley and Cragg, 2008), but there is no direct evidence to date that $\mathrm{DH} \beta \mathrm{E}$ can act at $\alpha 6: \beta 2$ subunit interfaces. Conversely, $\alpha$-Ctx MII (or $\alpha$-Ctx PIA) appears to act at low nanomolar concentrations at $\alpha 6: \beta 2$ subunit interfaces (Exley and Cragg, 2008). The sensitivity of mIPSC responses to $\alpha$-Ctx MII and $\alpha$-Ctx PIA at nanomolar concentrations also would exclude contributions of $\alpha 4 \beta 2-n A C h R$ to control of GABA release, and the predominantly reverse pharmacology of postsynaptic response suggests predominance of $\alpha 4 \beta 2-\mathrm{nAChR}$ over $\alpha 6^{*}-$ nAChR on VTA DA neuronal soma. Collectively, and although a more detailed molecular description of the nAChR subtype(s) involved remains to be determined, pharmacological and genetic knock-out data strongly suggest that presynaptic nAChRs mediating ACh effects on GABA release onto DA neurons in the VTA contain at least $\alpha 6$ and $\beta 2$ subunits but likely do not contain $\alpha 4$ subunits.

\section{Nicotinic regulation of presynaptic $\alpha 6^{\star}-$ nAChRs: possible role in reward}

Nicotine increases VTA DA neuron firing and DA release onto its targets in the NAc and prefrontal cortex and activates these components of the reward pathway through complex mechanisms (Dani and De Biasi, 2001; Mansvelder et al., 2003). Presynaptic $\alpha 7-\mathrm{nAChRs} \mathrm{located} \mathrm{on} \mathrm{glutamatergic} \mathrm{presynaptic} \mathrm{terminals} \mathrm{in}$ the VTA, as well as postsynaptic $\alpha 4 \beta 2-$ nAChRs located on both DA and GABAergic somata, play important roles in increased DA neuronal activity (Mansvelder and McGehee, 2002; Pidoplichko et al., 2004). Recent evidence demonstrates that, like nAChR $\beta 2$ or $\alpha 4$ subunit $\mathrm{KO}$ mice, $\mathrm{nAChR} \alpha 6$ subunit $\mathrm{KO}$ mice fail to self-administer nicotine, and restoration of VTA $\alpha 6^{*}-\mathrm{nAChR}$ subunit expression results in the return of nicotine selfadministration (Pons et al., 2008). There is evidence that $\alpha 6^{*}-$ nAChRs located on DA neuronal terminals in the NAc are important in mediating nicotine self-administration (Pons et al., 2008). Here, we demonstrate an additional mechanism for nicotinic modulation of VTA DA neuronal function: presynaptic $\alpha 6^{*}$-nAChRs on GABAergic boutons in the VTA. Under normal conditions, presynaptic $\alpha 6^{\star}-\mathrm{nAChR}$ would be expected to mediate endogenous cholinergic modulation of GABAergic neuronal firing, resulting in tonic inhibition of DA neuronal activity. Nicotine-induced desensitization of the presynaptic $\alpha 6^{*}$ nAChRs at smoking-relevant doses would be expected to eliminate this tonic inhibition, evident in a loss of effect of ACh on mIPSC frequency. This disinhibition mechanism in VTA DA neurons may contribute to DA neuron activity-driven reward. Finally, the rebound in presynaptic $\alpha 6^{*}-n A C h R-m e d i a t e d$ GABA release activity observed after several days of withdrawal from chronic nicotinic administration might be relevant to craving and withdrawal effects. Therefore, the identification and characterization of presynaptic $\alpha 6^{*}-\mathrm{nAChRs}$ on GABAergic boutons associated with VTA DA neurons provides a new insight into the role of these $\alpha 6^{*}$-nAChRs in nicotinic regulation of VTA DA neuronal function. This regulatory role likely is an important component of reward circuit activity and function.

\section{References}

Akaike N, Moorhouse AJ (2003) Techniques: applications of the nervebouton preparation in neuropharmacology. Trends Pharmacol Sci 24:44-47.

Alkondon M, Pereira EF, Wonnacott S, Albuquerque EX (1992) Blockade of nicotinic currents in hippocampal neurons defines methyllycaconitine as a potent and specific receptor antagonist. Mol Pharmacol 41:802-808.

Alkondon M, Pereira EF, Cortes WS, Maelicke A, Albuquerque EX (1997) Choline is a selective agonist of alpha7 nicotinic acetylcholine receptors in the rat brain neurons. Eur J Neurosci 9:2734-2742.

Azam L, Winzer-Serhan UH, Chen Y, Leslie FM (2002) Expression of neuronal nicotinic acetylcholine receptor subunit mRNAs within midbrain dopamine neurons. J Comp Neurol 444:260-274.

Azam L, Chen Y, Leslie FM (2007) Developmental regulation of nicotinic acetylcholine receptors within midbrain dopamine neurons. Neuroscience 144:1347-1360.

Cartier GE, Yoshikami D, Gray WR, Luo S, Olivera BM, McIntosh JM (1996) A new alpha-conotoxin which targets alpha3beta2 nicotinic acetylcholine receptors. J Biol Chem 271:7522-7528.

Champtiaux N, Gotti C, Cordero-Erausquin M, David DJ, Przybylski C, Léna C, Clementi F, Moretti M, Rossi FM, Le Novère N, McIntosh JM, Gardier AM, Changeux JP (2003) Subunit composition of functional nicotinic receptors in dopaminergic neurons investigated with knock-out mice. J Neurosci 23:7820-7829.

Clarke PB (1991) Nicotinic receptor blockade therapy and smoking cessation. Br J Addict 86:501-505.

Dani JA, De Biasi M (2001) Cellular mechanisms of nicotine addiction. Pharmacol Biochem Behav 70:439-446.

Dani JA, Harris RA (2005) Nicotine addiction and comorbidity with alcohol abuse and mental illness. Nat Neurosci 8:1465-1470.

Dani JA, Heinemann S (1996) Molecular and cellular aspects of nicotine abuse. Neuron 16:905-908.

Deng C, Li KY, Zhou C, Ye JH (2009) Ethanol enhances glutamate transmission by retrograde dopamine signaling in a postsynaptic neuron/ synaptic bouton preparation from the ventral tegmental area. Neuropsychopharmacology 34:1233-1244.

Doi A, Ishibashi H, Jinno S, Kosaka T, Akaike N (2002) Presynaptic inhibition of GABAergic miniature currents by metabotropic glutamate receptor in the rat CNS. Neuroscience 109:299-311.

Dowell C, Olivera BM, Garrett JE, Staheli ST, Watkins M, Kuryatov A, Yoshikami D, Lindstrom JM, McIntosh JM (2003) $\alpha$-Conotoxin PIA is selective for $\alpha 6$ subunit-containing nicotinic acetylcholine receptors. J Neurosci 23:8445-8452. 
Drenan RM, Grady SR, Whiteaker P, McClure-Begley T, McKinney S, Miwa JM, Bupp S, Heintz N, McIntosh JM, Bencherif M, Marks MJ, Lester HA (2008) In vivo activation of midbrain dopamine neurons via sensitized, high-affinity alpha 6 nicotinic acetylcholine receptors. Neuron 60: 123-136.

Dunkley PR, Jarvie PE, Heath JW, Kidd GJ, Rostas JA (1986) A rapid method for isolation of synaptosomes on Percoll gradients. Brain Res 372:115-129.

Endo T, Yanagawa Y, Obata K, Isa T (2005) Nicotinic acetylcholine receptor subtypes involved in facilitation of GABAergic inhibition in mouse superficial superior colliculus. J Neurophysiol 94:3893-3902.

Exley R, Clements MA, Hartung H, McIntosh JM, Cragg SJ (2008) Alpha6-containing nicotinic acetylcholine receptors dominate the nicotine control of dopamine neurotransmission in nucleus accumbens. Neuropsychopharmacology 33:2158-2166.

Good CH, Lupica CR (2009) Properties of distinct ventral tegmental area synapses activated via pedunculopontine or ventral tegmental area stimulation in vitro. J Physiol 587:1233-1247.

Gotti C, Moretti M, Clementi F, Riganti L, McIntosh JM, Collins AC, Marks MJ, Whiteaker P (2005) Expression of nigrostriatal alpha 6-containing nicotinic acetylcholine receptors is selectively reduced, but not eliminated, by beta 3 subunit gene deletion. Mol Pharmacol 67:2007-2015.

Grady SR, Drenan RM, Breining SR, Yohannes D, Wageman CR, Fedorov NB, McKinney S, Whiteaker P, Bencherif M, Lester HA, Marks MJ (2010) Structural differences determine the relative selectivity of nicotinic compounds for native alpha 4 beta $2^{\star}$-, alpha 6 beta $2^{\star}$-, alpha 3 beta $4^{*}$ - and alpha 7 -nicotine acetylcholine receptors. Neuropharmacology 58:1054-1066.

Harvey SC, Luetje CW (1996) Determinants of competitive antagonist sensitivity on neuronal nicotinic receptor $\beta$ subunits. J Neurosci 16: $3798-3806$.

Harvey SC, Maddox FN, Luetje CW (1996) Multiple determinants of dihydro-beta-erythroidine sensitivity on rat neuronal nicotinic receptor alpha subunits. J Neurochem 67:1953-1959.

Heimer L, Zahm DS, Churchill L, Kalivas PW, Wohltmann C (1991) Specificity in the projection patterns of accumbal core and shell in the rat. Neuroscience 41:89-125.

Kalivas PW, Churchill L, Klitenick MA (1993) GABA and enkephalin projection from the nucleus accumbens and ventral pallidum to the ventral tegmental area. Neuroscience 57:1047-1060.

Keath JR, Iacoviello MP, Barrett LE, Mansvelder HD, McGehee DS (2007) Differential modulation by nicotine of substantia nigra versus ventral tegmental area dopamine neurons. J Neurophysiol 98:3388-3396.

Klink R, de Kerchove d'Exaerde A, Zoli M, Changeux JP (2001) Molecular and physiological diversity of nicotinic acetylcholine receptors in the midbrain dopaminergic nuclei. J Neurosci 21:1452-1463.

Le Novère N, Zoli M, Changeux JP (1996) Neuronal nicotinic receptor alpha 6 subunit mRNA is selectively concentrated in catecholaminergic nuclei of the rat brain. Eur J Neurosci 8:2428-2439.

Mansvelder HD, McGehee DS (2002) Cellular and synaptic mechanisms of nicotine addiction. J Neurobiol 53:606-617.

Mansvelder HD, Keath JR, McGehee DS (2002) Synaptic mechanisms underlie nicotine-induced excitability of brain reward areas. Neuron 33:905-919.

Mansvelder HD, De Rover M, McGehee DS, Brussaard AB (2003) Cholinergic modulation of dopaminergic reward areas: upstream and downstream targets of nicotine addiction. Eur J Pharmacol 480:117-123.

Mansvelder HD, van Aerde KI, Couey JJ, Brussaard AB (2006) Nicotinic modulation of neuronal networks: from receptors to cognition. Psychopharmacology (Berl) 184:292-305.

McIntosh JM, Azam L, Staheli S, Dowell C, Lindstrom JM, Kuryatov A, Garrett JE, Marks MJ, Whiteaker P (2004) Analogs of alpha-conotoxin MII are selective for alpha6-containing nicotinic acetylcholine receptors. Mol Pharmacol 65:944-952.

Meyer EL, Yoshikami D, McIntosh JM (2008) The neuronal nicotinic acetylcholine receptors alpha $4^{*}$ and alpha $6^{*}$ differentially modulate dopamine release in mouse striatal slices. J Neurochem 105:1761-1769.

Mogg AJ, Whiteaker P, McIntosh JM, Marks M, Collins AC, Wonnacott S (2002) Methyllycaconitine is a potent antagonist of alpha-conotoxinMII-sensitive presynaptic nicotinic acetylcholine receptors in rat striatum. J Pharmacol Exp Ther 302:197-204.
Nayak SV, Dougherty JJ, McIntosh JM, Nichols RA (2001) $\mathrm{Ca}^{2+}$ changes induced by different presynaptic nicotinic receptors in separate populations of individual striatal nerve terminals. J Neurochem 76:1860-1870.

Papke RL, Webster JC, Lippiello PM, Bencherif M, Francis MM (2000) The activation and inhibition of human nicotinic acetylcholine receptor by RJR-2403 indicate a selectivity for the alpha4beta2 receptor subtype. J Neurochem 75:204-216.

Paxinos G, Watson C (1998) The rat brain in stereotaxic coordinates, Ed 2. San Diego: Academic.

Pidoplichko VI, DeBiasi M, Williams JT, Dani JA (1997) Nicotine activates and desensitizes midbrain dopamine neurons. Nature 390:401-404.

Pidoplichko VI, Noguchi J, Areola OO, Liang Y, Peterson J, Zhang T, Dani JA (2004) Nicotinic cholinergic synaptic mechanisms in the ventral tegmental area contribute to nicotine addiction. Learn Mem 11:60-69.

Pons S, Fattore L, Cossu G, Tolu S, Porcu E, McIntosh JM, Changeux JP, Maskos U, Fratta W (2008) Crucial role of $\alpha 4$ and $\alpha 6$ nicotinic acetylcholine receptor subunits from ventral tegmental area in systemic nicotine self-administration. J Neurosci 28:12318-12327.

Rowell PP, Li M (1997) Dose-response relationship for nicotine-induced up-regulation of rat brain nicotinic receptors. J Neurochem 68: 1982-1989.

Salminen O, Murphy KL, McIntosh JM, Drago J, Marks MJ, Collins AC, Grady SR (2004) Subunit composition and pharmacology of two classes of striatal presynaptic nicotinic acetylcholine receptors mediating dopamine release in mice. Mol Pharmacol 65:1526-1535.

Salminen O, Drapeau JA, McIntosh JM, Collins AC, Marks MJ, Grady SR (2007) Pharmacology of alpha-conotoxin MII-sensitive subtypes of nicotinic acetylcholine receptors isolated by breeding of null mutant mice. Mol Pharmacol 71:1563-1571.

Shytle RD, Silver AA, Lukas RJ, Newman MB, Sheehan DV, Sanberg PR (2002) Nicotinic acetylcholine receptors as targets for antidepressants. Mol Psychiatry 7:525-535.

Steffensen SC, Svingos AL, Pickel VM, Henriksen SJ (1998) Electrophysiological characterization of GABAergic neurons in the ventral tegmental area. J Neurosci 18:8003-8015.

Trigo FF, Bouhours B, Rostaing P, Papageorgiou G, Corrie JE, Triller A, Ogden D, Marty A (2010) Presynaptic miniature GABAergic currents in developing interneurons. Neuron 66:235-247.

Whiteaker P, McIntosh JM, Luo S, Collins AC, Marks MJ (2000) 125Ialpha-conotoxin MII identifies a novel nicotinic acetylcholine receptor population in mouse brain. Mol Pharmacol 57:913-925.

Wonnacott S (1997) Presynaptic nicotinic ACh receptors. Trends Neurosci 20:92-98.

Wooltorton JR, Pidoplichko VI, Broide RS, Dani JA (2003) Differential desensitization and distribution of nicotinic acetylcholine receptor subtypes in midbrain dopamine areas. J Neurosci 23:3176-3185.

Wu J, George AA, Schroeder KM, Xu L, Marxer-Miller S, Lucero L, Lukas RJ (2004) Electrophysiological, pharmacological, and molecular evidence for alpha7-nicotinic acetylcholine receptors in rat midbrain dopamine neurons. J Pharmacol Exp Ther 311:80-91.

Xiao C, Yang KC, Zhou CY, Jin GZ, Wu J, Ye JH (2009a) Nicotine modulates GABAergic transmission to dopaminergic neurons in substantia nigra pars compacta. Acta Pharmacol Sin 30:851-858.

Xiao C, Shao XM, Olive MF, Griffin WC 3rd, Li KY, Krnjević K, Zhou C, Ye $\mathrm{JH}$ (2009b) Ethanol facilitates glutamatergic transmission to dopamine neurons in the ventral tegmental area. Neuropsychopharmacology 34:307-318

Yang K, Hu J, Lucero L, Liu Q, Zheng C, Zhen X, Jin G, Lukas RJ, Wu J (2009a) Distinctive nicotinic acetylcholine receptor functional phenotypes of rat ventral tegmental area dopaminergic neurons. J Physiol 587:345-361.

Yang KC, Jin GZ, Wu J (2009b) Mysterious alpha6-containing nAChRs: function, pharmacology, and pathophysiology. Acta Pharmacol Sin 30:740-751.

Ye JH, Zhang J, Xiao C, Kong JQ (2006) Patch-clamp studies in the CNS illustrate a simple new method for obtaining viable neurons in rat brain slices: glycerol replacement of $\mathrm{NaCl}$ protects CNS neurons. J Neurosci Methods 158:251-259.

Zahm DS (1989) The ventral striatopallidal parts of the basal ganglia in the rat. II. Compartmentation of ventral pallidal efferents. Neuroscience 30: $33-50$. 